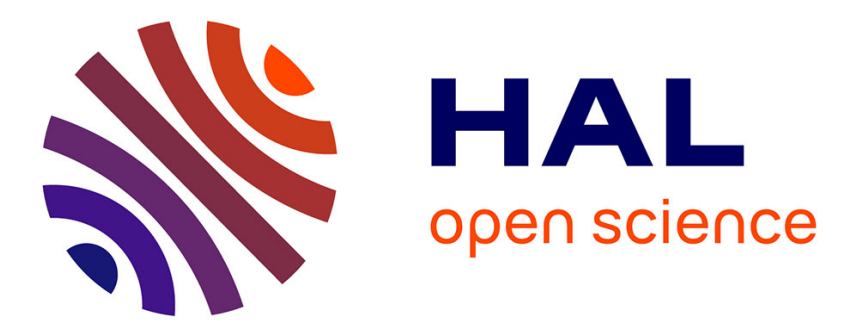

\title{
Structural analysis and multipole modelling of quercetin monohydrate - a quantitative and comparative study
}

Slawomir Domagala, Parthapratim Munshi, Maqsood Ahmed, Benoit Guillot, Christian Jelsch

\section{- To cite this version:}

Slawomir Domagala, Parthapratim Munshi, Maqsood Ahmed, Benoit Guillot, Christian Jelsch. Structural analysis and multipole modelling of quercetin monohydrate - a quantitative and comparative study. Acta Crystallographica Section B: Structural Science [1968-2013], 2011, 67 (1), pp.63-78. 10.1107/S0108768110041996 . hal-01710509

\author{
HAL Id: hal-01710509 \\ https://hal.science/hal-01710509
}

Submitted on 16 Feb 2018

HAL is a multi-disciplinary open access archive for the deposit and dissemination of scientific research documents, whether they are published or not. The documents may come from teaching and research institutions in France or abroad, or from public or private research centers.
L'archive ouverte pluridisciplinaire HAL, est destinée au dépôt et à la diffusion de documents scientifiques de niveau recherche, publiés ou non, émanant des établissements d'enseignement et de recherche français ou étrangers, des laboratoires publics ou privés. 


\title{
Science
}

ISSN 0108-7681

Editor: Carolyn P. Brock

\section{Structural analysis and multipole modelling of quercetin monohydrate - a quantitative and comparative study}

\author{
Sławomir Domagała, Parthapratim Munshi, Maqsood Ahmed, Benoît \\ Guillot and Christian Jelsch
}

Acta Cryst. (2011). B67, 63-78

Copyright (C) International Union of Crystallography

Author(s) of this paper may load this reprint on their own web site or institutional repository provided that this cover page is retained. Republication of this article or its storage in electronic databases other than as specified above is not permitted without prior permission in writing from the IUCr.

For further information see http://journals.iucr.org/services/authorrights.html

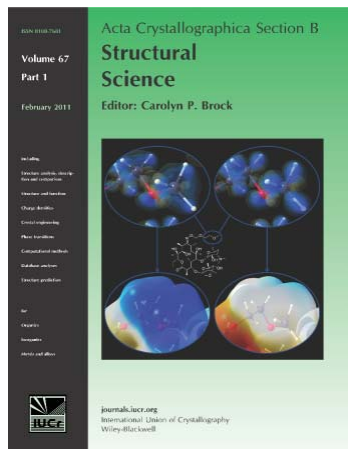

Acta Crystallographica Section B: Structural Science publishes papers in structural chemistry and solid-state physics in which structure is the primary focus of the work reported. The central themes are the acquisition of structural knowledge from novel experimental observations or from existing data, the correlation of structural knowledge with physicochemical and other properties, and the application of this knowledge to solve problems in the structural domain. The journal covers metals and alloys, inorganics and minerals, metal-organics and purely organic compounds.

Crystallography Journals Online is available from journals.iucr.org 
Acta Crystallographica Section B

Structural

Science

ISSN 0108-7681

Sławomir Domagała, Parthapratim Munshi, Maqsood Ahmed, Benoît Guillot and Christian Jelsch*

Laboratoire de Cristallographie, Résonance Magnétique et Modélizations (CRM2), CNRS, UMR 7036, Institut Jean Barriol, Faculté des Sciences et Techniques, Nancy Université, BP 70239, 54506 Vandoeuvre-lès-Nancy CEDEX, France

Correspondence e-mail:

christian.jelsch@crm2.uhp-nancy.fr

\section{Structural analysis and multipole modelling of quercetin monohydrate - a quantitative and comparative study}

The multipolar atom model, constructed by transferring the charge-density parameters from an experimental or theoretical database, is considered to be an easy replacement of the widely used independent atom model. The present study on a new crystal structure of quercetin monohydrate [2-(3,4dihydroxyphenyl)-3,5,7-trihydroxy-4H-chromen-4-one monohydrate], a plant flavonoid, determined by X-ray diffraction, demonstrates that the transferred multipolar atom model approach greatly improves several factors: the accuracy of atomic positions and the magnitudes of atomic displacement parameters, the residual electron densities and the crystallographic figures of merit. The charge-density features, topological analysis and electrostatic interaction energies obtained from the multipole models based on experimental database transfer and periodic quantum mechanical calculations are found to compare well. This quantitative and comparative study shows that in the absence of highresolution diffraction data, the database transfer approach can be applied to the multipolar electron density features very accurately.

\section{Introduction}

Quercetin is a naturally occurring flavonoid pigment found in coloured leafy vegetables, herbs and fruits. This biologically active compound has gained immense attention from the research community due to its medicinal properties. It is reported to possess anticancer (ElAttar \& Virji, 1999), antithrombotic (Gryglewski et al., 1987), antioxidant (Lamson \& Brignall, 2000) and antimicrobial (Formica \& Regelson, 1995; Gatto et al., 2002) properties. Recent research supports the idea that quercetin may be helpful for patients with chronic prostatitis with interstitial cystitis possibly because of its action as a mast cell inhibitor (Shoskes et al., 1999). The presence of quercetin along with other flavonols in our daily diet is also reported to be associated with a reduced risk of fatal pancreatic cancer in tobacco smokers (Nöthlings et al., 2007).

Charge-density analysis of accurate high-resolution singlecrystal X-ray diffraction data is now a matured branch of modern crystallography, published in a variety of journals, focusing on an ever-increasing range of inorganic, organometallic, organic and biological materials (Coppens, 1997; Spackman, 1997; Koritsánszky \& Coppens, 2001; Munshi \& Guru Row, 2005a). This technique has now reached a level at which the experimentally derived electron density can be compared with the charge density obtained from high-level theoretical calculations. Experimental and theoretical charge densities can be used to analyse a range of problems of chemical (Coppens, 1997) and physical (Tsirelson \& Ozerov,
Received 13 July 2010 Accepted 16 October 2010 
Table 1

Summary of the atom models.

\begin{tabular}{|c|c|}
\hline Model & Description \\
\hline IAM_R & $\begin{array}{l}x y z, \text { ADPs and scale factor refined versus experimental } \\
\text { structure factors } \\
X-\mathrm{H} \text { distances, angles involving } \mathrm{H} \text { atoms and ADPs of } \\
\text { the } \mathrm{H} \text { atoms restrained }\end{array}$ \\
\hline IAM_UR & $\begin{array}{l}x y z, \text { ADPs and scale factor refined versus experimental } \\
\text { structure factors } \\
\text { ADPs of the } \mathrm{H} \text { atoms restrained }\end{array}$ \\
\hline TAAM_R & $\begin{array}{l}x y z, \text { ADPs and scale factor refined versus experimental } \\
\text { structure factors } \\
X-\mathrm{H} \text { distances, angles involving } \mathrm{H} \text { atoms and ADPs of } \\
\text { the } \mathrm{H} \text { atoms restrained } \\
\text { Multipolar parameters transferred from the extended } \\
\text { database }\end{array}$ \\
\hline TAAM_UR & $\begin{array}{l}x y z, \text { ADPs and scale factor refined versus experimental } \\
\text { structure factors } \\
\text { ADPs of the H atoms } \\
\text { Multipolar parameters transferred from the extended } \\
\text { database }\end{array}$ \\
\hline TAAM_OPT & $\begin{array}{l}\text { Optimized geometry used } \\
\text { Multipolar parameters transferred from the extended } \\
\text { database }\end{array}$ \\
\hline THEO_OPT & $\begin{array}{l}\text { Optimized geometry used } \\
\text { Multipolar parameters refined versus theoretical struc- } \\
\text { ture factors } \\
\kappa \text { and } \kappa^{\prime} \text { parameters for some } \mathrm{H} \text { atoms restrained }\end{array}$ \\
\hline TAAM_THEO_R & $\begin{array}{l}x y z, \text { ADPs and scale factor refined versus experimental } \\
\text { structure factors } \\
X-\mathrm{H} \text { distances, angles involving } \mathrm{H} \text { atoms and ADPs of } \\
\text { the } \mathrm{H} \text { atoms restrained } \\
\text { Multipolar parameters transferred from the THEO_OPT } \\
\text { model }\end{array}$ \\
\hline
\end{tabular}

1996) interest since the charge density is a physically observable quantity. One of the most exciting applications of charge density analysis is the evaluation of one-electron properties in molecular crystals (Spackman, 1992).

Bader's Quantum Theory of Atoms In Molecules (QTAIM) is an ultimate approach to studying the topological features of the charge-density distribution (Bader, 1990, 1998). Topological analysis via the QTAIM approach is capable of providing the information about the existence and the nature of hydrogen bonds. The eight criteria suggested by Koch and Popelier (Koch \& Popelier, 1995; Popelier, 2000; hereafter referred as KP) based on QTAIM allow a hydrogen bond to be distinguished from a van der Waals interaction. In this study we focus on the first four of the criteria.<smiles>O=c1c(O)c(-c2ccc(O)c(O)c2)oc2cc(O)cc(O)c12</smiles>

Figure 1

Chemical structure of quercetin monohydrate.
The possibility of using previously extracted electrondensity parameters within Hirshfeld's (1971) aspherical formalism in crystallographic modelling was first realised by Brock et al. (1991). This work was followed by Pichon-Pesme et al. (1995), resulting in the construction of the first experimental database of peptide and amino-acid fragments, called the experimental library of multipolar atom models (ELMAM) based on the Hansen-Coppens (Hansen \& Coppens, 1978) multipolar formalism. Two more aspherical atom libraries based on the same formalism but using computed electron densities were also constructed: University at Buffalo Pseudoatom Databank (UBDB; Volkov et al., 2004) and the Invariom database (Dittrich et al., 2004). All three libraries are in continuous development and were revised several times. ELMAM was updated in 2004 (Pichon-Pesme et al., 2004), UBDB in 2007 (Dominiak et al., 2007) and Invariom was improved in 2006 (Dittrich, Hübschle et al., 2006). The advantages of using aspherical atom databases in routine crystallographic modelling were pointed out in several studies (Jelsch et al., 1998, 2005; Dittrich et al., 2005, 2007, 2008; Dittrich, Hübschle et al., 2006, 2009; Dittrich, Strümpel et al., 2006; Dittrich, Weber et al., 2009; Volkov et al., 2007; Zarychta et al., 2007; Back et al., 2009). Improvements to the residual electron density, geometrical parameters and atomic displacement parameters have been thoroughly discussed. Moreover, some of the databases were also used to compute the electrostatic interaction energies between host-guest protein complexes (Dominiak et al., 2009; Fournier et al., 2009).

The ELMAM database has been extended from protein atom types to common organic molecules and is based on the optimal local coordinate systems (Domagała \& Jelsch, 2008). New chemical environments (atom types) can be easily added to the database when new charge-density diffraction data become publicly available. Details of the construction of this extended database will be published in a separate paper. In this work we present the application of the extended database for the multipolar atom modelling of quercetin monohydrate (Fig. 1). The most important features of the modelled electron density of this compound are discussed and are the subject of a detailed comparison with the theoretical multipole model based on periodic quantum mechanical calculations. All the atom models discussed here are summarized in Table 1 . The charge-density parameters transferred to quercetin are described in the CIF files in the supplementary material. ${ }^{1}$

\section{Experimental and theoretical details}

\subsection{Crystallization, data collection and data reduction}

Quercetin dihydrate (CAS number 6151-25-3) purchased as a powder from Sigma-Aldrich was dissolved at $\sim 233 \mathrm{~K}$ in acetonitrile. The solution was left overnight to slowly cool down to room temperature. Yellow crystals of prismatic shape were crystallized from the solution. A crystal of size $0.35 \times$

\footnotetext{
${ }^{\mathbf{1}}$ Supplementary data for this paper are available from the IUCr electronic archives (Reference: GW5011). Services for accessing these data are described at the back of the journal.
} 
Table 2

Experimental details.

For all structures: $\mathrm{C}_{15} \mathrm{H}_{10} \mathrm{O}_{7} \cdot \mathrm{H}_{2} \mathrm{O}, M_{\mathrm{r}}=320.24$, monoclinic, $P 2_{1} / c, Z=4$. Experiments were carried out at $110 \mathrm{~K}$ with $\mathrm{Cu} \mathrm{K \alpha}$ radiation using a SuperNova, Dual, $\mathrm{Cu}$ at zero, Atlas diffractometer. Absorption was corrected for by multi-scan methods. 'Empirical absorption correction using spherical harmonics was implemented in the SCALE3 ABSPACK scaling algorithm.' Refinement was on 256 parameters with 29 restraints. $\mathrm{H}$-atom parameters were constrained.

\begin{tabular}{|c|c|c|c|}
\hline & IAM_R & TAAM_R & TAAM_THEO_R \\
\hline \multicolumn{4}{|l|}{ Crystal data } \\
\hline$a, b, c(\AA)$ & \multicolumn{3}{|c|}{8.737 (1), $4.852(1), 30.160$ (1) } \\
\hline$\beta\left(^{\circ}\right)$ & \multicolumn{3}{|l|}{$95.52(1)$} \\
\hline$V\left(\AA^{3}\right)$ & \multicolumn{3}{|l|}{$1272.6(3)$} \\
\hline$\mu\left(\mathrm{mm}^{-1}\right)$ & \multicolumn{3}{|l|}{0.138} \\
\hline Crystal size $(\mathrm{mm})$ & \multicolumn{3}{|l|}{$0.35 \times 0.19 \times 0.16$} \\
\hline \multicolumn{4}{|l|}{ Data collection } \\
\hline$T_{\min }, T_{\max }$ & \multicolumn{3}{|l|}{$0.672,1.000$} \\
\hline $\begin{array}{l}\text { No. of measured, independent and } \\
\text { observed }[I>2.0 \sigma(I)] \text { reflections }\end{array}$ & \multicolumn{3}{|l|}{$69706,2652,2565$} \\
\hline$R_{\text {int }}$ & \multicolumn{3}{|l|}{0.017} \\
\hline \multicolumn{4}{|l|}{ Refinement } \\
\hline$R\left[F^{2}>2 \sigma\left(F^{2}\right)\right], w R\left(F^{2}\right), S$ & $0.039,0.054,2.19$ & $0.020,0.028,1.11$ & $0.020,0.027,1.11$ \\
\hline No. of reflections & 2652 & 2652 & 2652 \\
\hline$\Delta \rho_{\max }, \Delta \rho_{\min }\left(\mathrm{e} \AA^{-3}\right)$ & $0.39,-0.24$ & $0.14,-0.16$ & $0.15,-0.18$ \\
\hline
\end{tabular}

Computer programs used: CrysAlisPro (Oxford Diffraction, 2009), SHELXL97 (Sheldrick, 2008), MoPro (Jelsch et al., 2005).

$0.19 \times 0.16 \mathrm{~mm}$ was selected for the experiment. Data collection was performed using an Oxford Diffraction SuperNova Dual Wavelength Microfocus diffractometer equipped with an ATLAS CCD detector. Reflections were collected at $110 \mathrm{~K}$ up to $\sin \theta / \lambda=0.63 \AA^{-1}$ resolution using $\mathrm{Cu}$ radiation. Data were collected using $91 \omega$ runs, with a $1.0^{\circ}$ scan width and $15 \mathrm{~s}$ per frame exposure time, resulting in a total of 4921 frames. The average redundancy was 6.7. Indexing, integration and scaling were performed with CrysAlisPro, Version 1.171 (Oxford Diffraction, 2009). In total, 39962 reflections were measured and then merged to 2652 unique reflections. The multi-scan absorption correction was applied in the scaling procedure. Further details of the data collection and reduction are given in Table 2.

\subsection{Spherical atom refinements}

Structure solution and the initial stages of refinement were carried out using SHELX 97 (Sheldrick, 2008) with full-matrix least-squares and based on $F^{2}$. The final refinements on $F$ were performed using the MoPro package (Guillot et al., 2001; Jelsch et al., 2005).

\subsection{Theoretical calculations}

Periodic quantum mechanical calculations using CRYSTAL06 (Dovesi et al., 2008) were performed for the crystal structure obtained from X-ray diffraction and, using this as a starting point, full geometry optimization was performed using density functional theory (DFT; Hohenberg $\&$ Kohn, 1964) and with the B3LYP hybrid functional (Lee $e t$ al., 1988; Becke, 1993) using the 6-31G(d,p) basis set (Hari- haran \& Pople, 1973). Upon energy convergence $\left(\Delta E \simeq 10^{-6}\right)$, a periodic wavefunction based on optimized geometry was obtained. The index generation scheme proposed by Le Page \& Gabe (1979) was applied to generate 18404 unique Miller indices up to $1.2 \AA^{-1}$ reciprocal resolution. Option XFAC of the CRYSTAL06 program was then used to generate a set of theoretical structure factors from the computed electron density and using a set of prepared indices.

\subsection{Experimental modelling}

Initially the quercetin monohydrate structure was modelled using the independent atom model (IAM) approximation. Atomic displacement parameters (ADPs), positions ( $x y z$ coordinates) and the scale factor were refined with the appropriate weighting scheme and restraints. $X-\mathrm{H}$ (where $X=\mathrm{C}$ or $\mathrm{O}$ ) distances were shifted and restrained to the average neutron diffraction distances (Allen et al., 1987, 2006). Angles involving $\mathrm{C}-\mathrm{H}$ bonds were also restrained using similarity restraints. The ADPs of the $\mathrm{H}$ atoms were scaled according to $U_{\text {eq }}$ of the carrying atoms (URATIO restraint) in an analogous way to SHELX (Sheldrick, 2008). This restrained model is referred to as the IAM_R model (Table 1). Further, restraints on the distances and angles were released from IAM_R, while the URATIO restraints were maintained. This partially unrestrained model is referred to as IAM_UR (Table 1).

\subsection{Database transfer}

A total of 12 unique atom types from the extended ELMAM database were assigned to 35 atoms of quercetin monohydrate. For some atoms, the same atom type was selected (see Table S1 of the supplementary material). The multipolar parameters (including $\kappa$ and $\kappa^{\prime}$ ) were then transferred to the quercetin monohydrate structure resulting from the final IAM_R and IAM_UR models. The corresponding transferred aspherical atom models (TAAM) are referred to as TAAM_R and TAAM_UR (Table 1). Subsequently, the charge-density parameters were kept fixed and the ADPs, atomic positions and the scale factor were refined until convergence was reached. The same weighting scheme and restraints were applied as in the IAM_R and IAM_UR models. Further, the multipolar parameters from the extended ELMAM database were transferred to the set of coordinates obtained from the optimized quercetin monohydrate structure. The resulting model is referred to as TAAM_OPT (Table 1).

For all TAAM models, constructed using the extended ELMAM database, the electron density of the non-H atoms was described up to octupolar level, while for $\mathrm{H}$ atoms it was described only for the bond-directed quadrupole $\left(q_{3 z^{2}-1}\right)$ and 
dipole $\left(d_{z}\right)$ components along with the monopole function. After transfer, the resulting excess charge for the quercetin monohydrate was -0.765 e $(-0.022$ e per atom on average). Therefore, the quercetin molecule and water molecule were neutralized separately, using the charge-scaling procedure of Faerman \& Price (1990).

\subsection{Theoretical modelling}

The MoPro package was used to perform the multipolar refinement (based on $F$ ) against the whole set of generated theoretical structure factors. The corresponding model is referred to as THEO_OPT (Table 1). The non-H atoms were modelled up to the octupolar level. All $\mathrm{H}$ atoms were refined with one dipole $d_{z}$ component, except the $\mathrm{H}$ atoms connected to the $\mathrm{O}$ atoms for which a quadrupole $q_{3 z^{2}-1}$ component was also refined. The scale factor was fixed to the absolute value (1.0). To consider a static model, the $U^{i j}$ tensor elements were set to zero. During the refinement only valence and multipole populations, and $\kappa$ and $\kappa^{\prime}$ parameters were allowed to refine, but no atomic positions were refined. No restraints/constraints were imposed on any atoms, except $\kappa$ constraints on the $\mathrm{H}$ atoms. In particular, one set of $\kappa$ and $\kappa^{\prime}$ parameters was used for all $\mathrm{H}$ atoms of the hydroxyl groups and a separate $\left(\kappa, \kappa^{\prime}\right)$ set was used for $\mathrm{H}$ atoms bound to the $\mathrm{C}$ atoms. An independent $\left(\kappa, \kappa^{\prime}\right)$ set was defined for the H6 atom as initial theoretical refinements showed dissimilar values. However, the final $\kappa$ and $\kappa^{\prime}$ values of the H6 atom [1.149 (5) and $\left.1.36(1)\right]$ were very similar to those of other $\mathrm{H}$ atoms [1.162 (3) and 1.35 (1)] bound to the $\mathrm{C}$ atoms. The $\mathrm{H}$ atoms of the water molecule shared a fourth set of $\kappa$ and $\kappa^{\prime}$ parameters. In order to keep both molecules neutral and to allow better comparison with the transferred model, during the refinement no charge transfer was allowed between the quercetin and the water molecule.

Additionally, the multipolar parameters from the THEO_OPT model were transferred to the IAM_R model and only the ADPs, atomic positions and the scale factor were re-refined against the experimentally observed reflections. The same type and number of restraints and weighting scheme as used for other restrained models were also applied in this model. The corresponding model is referred to as TAAM_THEO_R (Table 1).

\subsection{Electrostatic interaction energy}

All the electrostatic interaction energy computations were performed with VMoPro, part of the MoPro package, using the numerical integration method on a spherical grid around selected atoms. The Gauss-Chebyshev (Becke, 1988) and Lebedev \& Laikov (1999) quadratures were used for the radial and angular parts, respectively. Radial coordinates and weights were remapped using the formula of Treutler \& Ahlrichs (1995). The integrations involved 100 radial and 434 angular quadrature points. Interaction energies were calculated between pairs of neighboring molecules in contact, for which two atoms were separated by a distance lower than or equal to the sum of their van der Waals radii.
The interaction energy values were computed as an integral over the electron density (obtained from the multipolar refinement) of molecule $A$ multiplied by the electrostatic potential of molecule $B$, or reciprocally

$$
E_{\text {elec }}=\int \rho_{A} \varphi_{B} \mathrm{~d} r_{A}=\int \rho_{B} \varphi_{A} \mathrm{~d} r_{B} .
$$

\section{Results and discussions}

\subsection{Crystal structure}

Here we report the structure of a new hydrate form of quercetin crystallized in the monoclinic centrosymmetric space group $P 2_{1} / c$ with $Z=4$ determined from $\mathrm{X}$-ray diffraction data. In the present case quercetin crystallized with one water molecule in the asymmetric unit. The structural details and the statistical parameters from the spherical atom refinement of X-ray diffraction data are listed in Tables 2 and

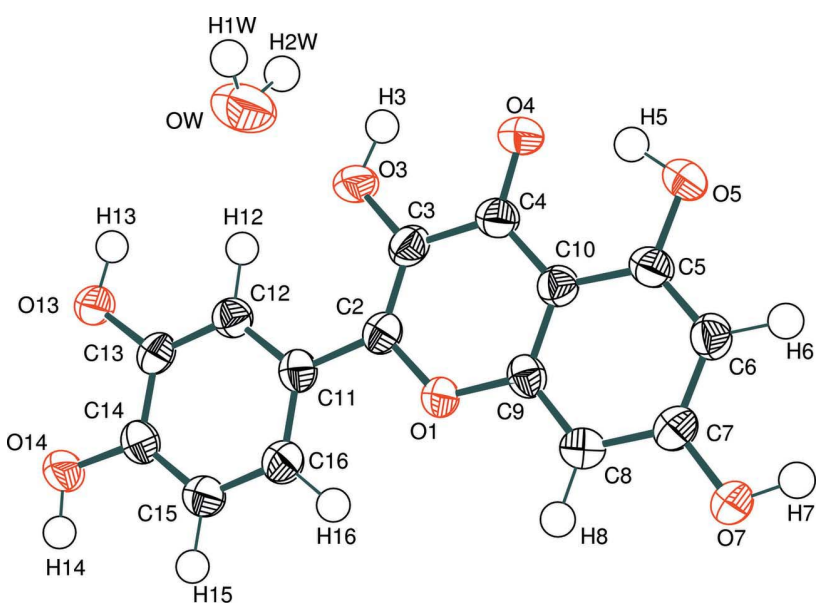

(a)

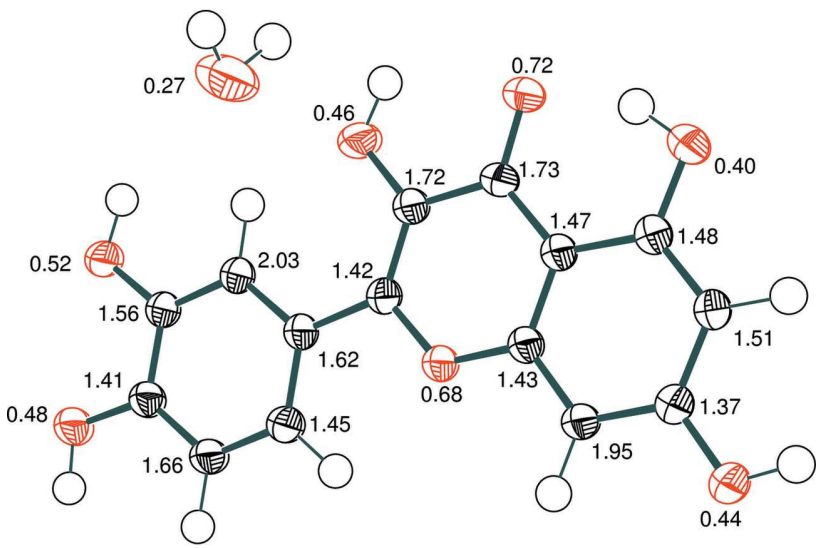

(b)

Figure 2

ORTEP diagram of quercetin monohydrate at $110 \mathrm{~K}$ with $90 \%$ probability ellipsoids showing $(a)$ the atomic labelling scheme and $(b)$ the $S_{12}$ similarity index (Whitten \& Spackman, 2006) values. The ellipsoid diagrams from $(a)$ IAM_R and $(b)$ TAAM_R models were generated using ORTEPIII (Johnson \& Burnett, 1996; Farrugia, 1997). 
Table 3

Final refinement statistics from different atom models.

\begin{tabular}{llllll}
\hline Models & IAM_R & IAM_UR & TAAM_R & TAAM_UR & TAAM_THEO_R \\
\hline $\begin{array}{l}\text { No. of restraints } \\
\text { No. of parameters } \dagger\end{array}$ & 29 & 12 & 29 & 12 & 29 \\
Final $R$ indices $[I / \sigma>0]$ & & 256 & 256 & 256 & 256 \\
$R(F)$ & 0.0400 & 0.0384 & 0.0220 & 0.0219 & 0.0219 \\
$w R^{2}(F)$ & 0.0542 & 0.0511 & 0.0275 & 0.0267 & 0.0274 \\
Goodness-of-fit $[S(F)]$ & 2.190 & 2.071 & 1.109 & 1.084 & 1.106 \\
$(\Delta / \sigma)_{\max }$ & $<0.001$ & $<0.001$ & $<0.001$ & $<0.001$ & $<0.001$ \\
$\Delta \rho_{\max }\left(\mathrm{e} \AA^{-3}\right)$ & 0.394 & 0.327 & 0.139 & 0.140 & 0.152 \\
$\Delta \rho_{\min }\left(\mathrm{e} \AA^{-3}\right)$ & -0.242 & -0.262 & -0.157 & -0.172 & -0.180 \\
\hline
\end{tabular}

$\dagger$ Including restraint parameters.

Table 4

Comparison of selected torsion angles for quercetin monohydrate and dihydrate structures.

\begin{tabular}{llll}
\hline & \multicolumn{2}{l}{ Present work } & \\
\cline { 2 - 3 } Torsion angles $\left(^{\circ}\right)$ & X-ray (IAM_R) & Optimized & Jin et al. $(1990)$ (X-ray) \\
\hline $\mathrm{C} 3-\mathrm{C} 2-\mathrm{C} 11-\mathrm{C} 12$ & $-1.3(1)$ & -2.7 & 171.4 \\
$\mathrm{C} 3-\mathrm{C} 2-\mathrm{C} 11-\mathrm{C} 16$ & $178.3(1)$ & 176.6 & -6.6 \\
$\mathrm{O} 1-\mathrm{C} 2-\mathrm{C} 11-\mathrm{C} 16$ & $-1.0(1)$ & -2.5 & 175.0 \\
$\mathrm{O} 1-\mathrm{C} 2-\mathrm{C} 11-\mathrm{C} 12$ & $179.4(1)$ & 178.3 & -6.9 \\
\hline
\end{tabular}

3. The ORTEP (Johnson \& Burnett, 1996; Farrugia, 1997) diagram, along with atom labeling of the quercetin and water molecules, is displayed in Fig. 2(a).

There are two structure determinations of quercetin dihydrate which have been previously published (Rossi et al., 1986; Jin et al., 1990). Here we compare the present monohydrate structure with the quercetin dihydrate structure determined by Jin et al. (1990) at room temperature using X-ray diffraction data, which seems to be more accurate, in terms of $R$ factors and the height of the residual electron-density peaks, than the first report of quercetin dihydrate (Rossi et al., 1986). Comparison is also drawn with the monohydrate structure obtained from geometry optimization calculations. The most notable difference in the geometry of the quercetin molecule is the different conformation of the catechol ring, which exhibits the free rotation possibility around the $\mathrm{C} 2-\mathrm{C} 11$

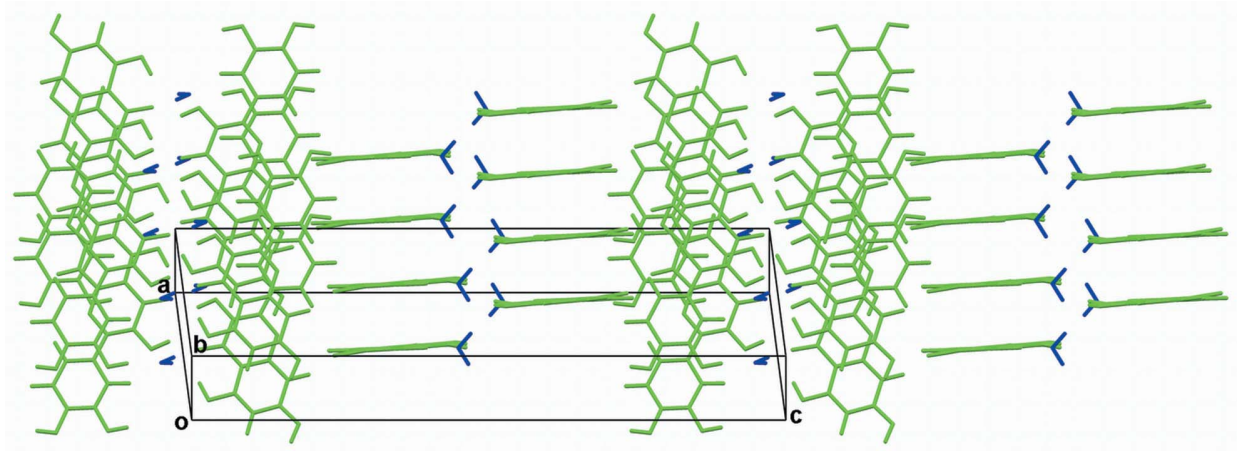

Figure 3

Molecular packing in the quercetin monohydrate structure showing the $A A B B$ stacking pattern. Quercetin and water molecules are highlighted in green and dark blue colours. This figure is in colour in the electronic version of this paper. bond. In the case of the quercetin dihydrate structure, the dihedral angle (O1-C2$\mathrm{C} 11-\mathrm{C} 16)$ between the benzopyran rings and the catechol ring is $175.0^{\circ}$ (anti orientation). On the contrary, the quercetin molecule of the monohydrate structure is almost planar and the catechol ring is rotated by $\sim 180^{\circ}$ (syn orientation), the dihedral angle $\mathrm{O} 1-$ $\mathrm{C} 2-\mathrm{C} 11-\mathrm{C} 16$ is $-1.0(1)^{\circ}\left(-2.5^{\circ}\right.$ for the optimized geometry). A comparison of the relevant torsion angles with respect to the $\mathrm{C} 2-\mathrm{C} 11$ bond is presented in Table 4. Based on their INDO calculation, Jin et al. (1990) found that the stable conformation of quercetin has a $\mathrm{C} 3-\mathrm{C} 2-\mathrm{C} 11-\mathrm{C} 16$ torsion angle of nearly 0 or $180^{\circ}$. Furthermore, DFT calculations in the gas phase and solution proved that the syn conformer seems to be preferred over the anti form with a small barrier of interconversion, suggesting the coexistence of two conformers (Leopoldini et al., 2004). Recently, Olejniczak \& Potrzebowski (2004) reported solid-state ${ }^{13} \mathrm{C}$ NMR studies for the anhydrous and dihydrate forms of quercetin. These experimental measurements were supported by gauge-including atomic orbital DFT calculations of ${ }^{13} \mathrm{C}$ NMR parameters for several possible conformations of quercetin, including the syn conformer, which is analogous to the quercetin monohydrate structure. The calculated ${ }^{13} \mathrm{C}$ shielding parameters $\sigma$ and bond-order parameters indicate that the quercetin monohydrate with syn conformation is the favoured one (Olejniczak \& Potrzebowski, 2004).

In the present structure the quercetin molecules pack in the crystal lattice in such a fashion that they follow the $A A B B$ stacking pattern (Fig. 3). The water molecules are found to be trapped at the interface of the same type of molecule, i.e. between $A A$-type and between $B B$-type stacking. It is to be noted that $A$ and $B$ are the same molecule and are related by crystallographic symmetry. For both types of stacking ( $A A$ and $B B)$, the inter-planar distance between the benzopyran rings is 3.276 (5) $\AA$ and that between the phenyl rings is 3.310 (5) $\AA$. While viewed down the $c$ axis, the molecules are found to intersect each other almost perpendicularly (inter-planar angle $\sim 85^{\circ}$ ) to form the parallel stripes of the 'fishing net' running along the $a$ axis (Fig. 4).

The intra- and intermolecular hydrogen bonds and their characterizing parameters in quercetin monohydrate are listed in Table 5. There are five hydroxyl groups in the quercetin molecule and four of them are involved in $\mathrm{O}-\mathrm{H} \cdots \mathrm{O}$ strong intermolecular hydrogen bonds. However, the hydroxyl group at position C5 has an intramolecular hydrogen bond with the $\mathrm{O} 4$ carbonyl $\mathrm{O}$ atom, which essentially forms a six-membered 'ring'. 
There is an additional weak intramolecular contact [C12H12 $\cdots \mathrm{O} 3=2.057$ (12) $\AA$ ], which also forms a six-membered 'ring'. The water molecule bridging the same type of molecule $(A A$ and $B B)$ via $\mathrm{O}-\mathrm{H} \cdots \mathrm{O}$ and $\mathrm{C}-\mathrm{H} \cdots \mathrm{O}$ hydrogen bonds plays a major role in the formation of three-dimensional networks (Table 5).

To facilitate the discussion on intermolecular contacts in quercetin monohydrate, a Hirshfeld surface analysis (Spackman \& McKinnon, 2002; McKinnon et al., 2004) was performed with CrystalExplorer (Wolff et al., 2007). It has been shown recently that tools based on Hirshfeld surfaces are a very powerful resource for quantifying intermolecular interactions in molecular crystals (McKinnon et al., 2007). Details of the Hirshfeld surface approach are discussed elsewhere (Spackman \& McKinnon, 2002; McKinnon et al., 2004; Munshi, Skelton et al., 2008). Fig. 5 depicts the relative contributions to the Hirshfeld surface areas due to $\mathrm{H} \cdots \mathrm{H}$, $\mathrm{O} \cdots \mathrm{H}, \mathrm{C} \cdots \mathrm{H}$ and other intermolecular contacts (i.e. all $\mathrm{O} \cdots \mathrm{O}, \mathrm{O} \cdots \mathrm{C}$ and $\mathrm{C} \cdots \mathrm{C}$ ). From this quantitative analysis it is clear that the quercetin monohydrate contains a low fraction $(13 \%)$ of $\mathrm{H} \cdots \mathrm{C}$ (i.e. $\mathrm{C}-\mathrm{H} \cdots \mathrm{C}$ or $\mathrm{O}-\mathrm{H} \cdots \mathrm{C})$ contacts. The $\mathrm{H} \cdots \mathrm{O}$ contacts constitute the highest fraction (36\%). The majority of these are $\mathrm{O}-\mathrm{H} \cdots \mathrm{O}$ contacts, the dominating hydrogen bonds in this crystal structure (Table 5), rather than $\mathrm{C}-\mathrm{H} \cdots \mathrm{O}$ contacts. Further quantitative and qualitative

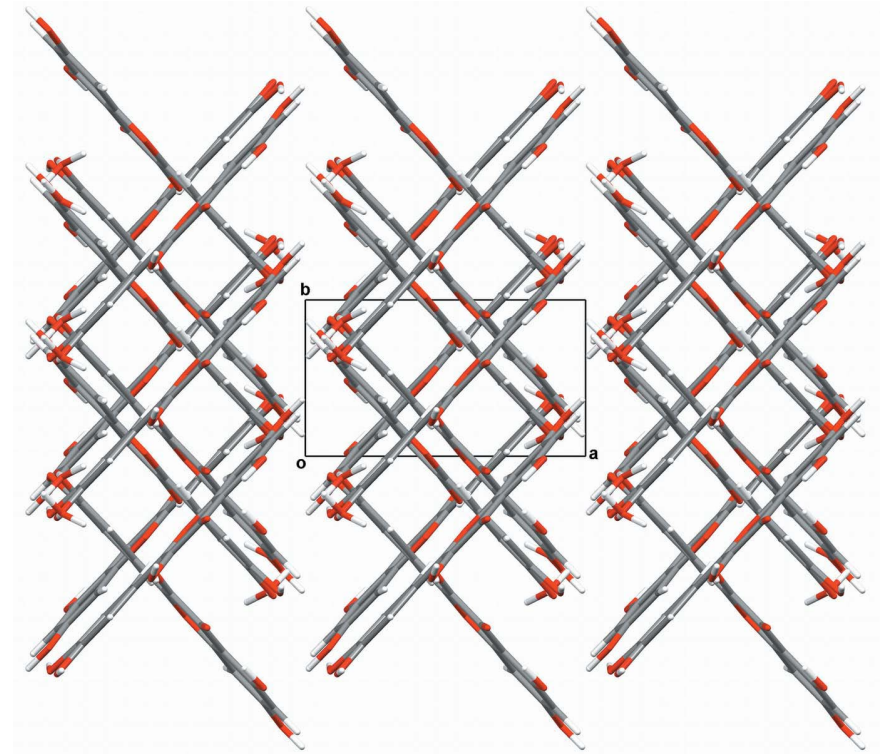

Figure 4

The 'fishing net' pattern of quercetin monohydrate. View along the $c$ axis.

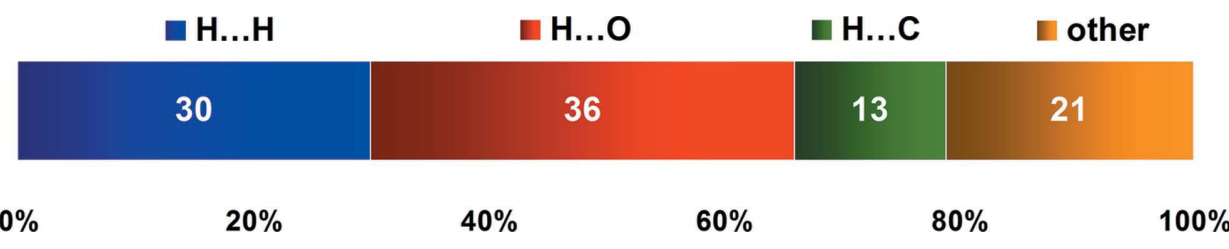

Figure 5

Relative contributions of the intermolecular contacts in the quercetin monohydrate structure using Hirshfeld surface analysis. The chart is based on the IAM_R model.
Table 5

Intra- and intermolecular contacts obtained from the IAM_R model of quercetin monohydrate.

\begin{tabular}{|c|c|c|c|c|}
\hline$D-\mathrm{H} \cdots A$ & $D-\mathrm{H}(\AA)$ & $\mathrm{H} \cdots A(\AA)$ & $D \cdots A(\AA)$ & $\angle D-\mathrm{H} \cdots A\left(^{\circ}\right)$ \\
\hline $\mathrm{O} 3-\mathrm{H} 3 \cdots \mathrm{O} 4^{\mathrm{i}}$ & 0.966 & 1.919 & $2.708(1)$ & 137.0 \\
\hline $\mathrm{O} 5-\mathrm{H} 5 \cdots \mathrm{O} 4^{\mathrm{ii}}$ & 0.967 & 1.714 & $2.608(1)$ & 152.2 \\
\hline $\mathrm{O} 7-\mathrm{H} 7 \cdots \mathrm{O} 13^{\mathrm{iii}}$ & 0.966 & 1.813 & $2.779(1)$ & 179.5 \\
\hline $\mathrm{O} 13-\mathrm{H} 13 \cdots \mathrm{O} 1 W^{\mathrm{iv}}$ & 0.966 & 1.759 & $2.713(1)$ & 168.8 \\
\hline $\mathrm{O} 14-\mathrm{H} 14 \cdots \mathrm{O}^{\mathrm{v}}$ & 0.967 & 1.835 & $2.802(1)$ & 179.4 \\
\hline $\mathrm{O} 1 W-\mathrm{H} 2 W \cdots \mathrm{O} 4^{\mathrm{i}}$ & 0.967 & 1.942 & $2.906(1)$ & 175.4 \\
\hline $\mathrm{O} 1 W-\mathrm{H} 1 W \cdots \mathrm{O} 5^{\mathrm{vi}}$ & 0.967 & 2.200 & $3.045(2)$ & 145.3 \\
\hline $\mathrm{O} 1 W-\mathrm{H} 1 W \cdots \mathrm{O} 5^{\mathrm{vii}}$ & 0.967 & 2.350 & $3.043(2)$ & 128.1 \\
\hline $\mathrm{C} 6-\mathrm{H} 6 \cdots \mathrm{O} 13^{\mathrm{iii}}$ & 1.081 & 2.530 & $3.308(2)$ & 128.1 \\
\hline $\mathrm{C} 6-\mathrm{H} 6 \cdots \mathrm{O} 1 W^{\mathrm{viii}}$ & 1.081 & 2.604 & $3.662(2)$ & 165.9 \\
\hline $\mathrm{C} 12-\mathrm{H} 12 \cdots \mathrm{O} 3^{\mathrm{ii}}$ & 1.082 & 2.057 & $2.812(2)$ & 124.3 \\
\hline $\mathrm{C} 12-\mathrm{H} 12 \cdots \mathrm{O} 1 W^{\mathrm{iv}}$ & 1.081 & 2.764 & $3.501(2)$ & 125.2 \\
\hline $\mathrm{C} 15-\mathrm{H} 15 \cdots \mathrm{O}^{\mathrm{v}}$ & 1.082 & 2.578 & $3.367(2)$ & 129.1 \\
\hline
\end{tabular}

Symmetry codes: (i) $1-x, 1-y,-z$; (ii) $x, y, z$; (iii) $-1+x,-2+y, z$; (iv) $x, 1+y, z$; (v) $1-x, \frac{3}{2}+y, \frac{1}{2}-z$; (vi) $1+x, y, z$; (vii) $1-x,-y,-z$; (viii) $-1+x,-1+y, z$.

analyses of intermolecular contacts based on their topological properties derived using Bader's (1990, 1998) QTAIM (quantum theory of atoms in molecules) approach are discussed in a later section.

\subsection{Improvement over spherical atom model}

In this section we draw comparisons between IAM_R versus TAAM_R and IAM_UR versus TAAM_UR models. The final statistics are given in Table 3 .

In order to check the improvement of $X-\mathrm{H}$ distances, restraints on distances and angles were released from the restrained models. Indeed the introduction of multipolar parameters from the extended ELMAM database in the TAAM_UR model greatly improves the values of the $X-\mathrm{H}$ distances on average. The distance values are more similar to the average neutron distances (Allen et al., 1987, 2006) than those obtained from the IAM_UR model. Similar trends were also observed from other studies based on multipolar databases (Zarychta et al., 2007; Dittrich et al., 2005; Dittrich, Weber et al., 2009). The deviation from the neutron mean distances, defined as $d_{\text {model }}-d_{\text {neutron }}$, is smaller than $1 \sigma_{\text {neut }}$ for $\mathrm{O}-\mathrm{H}$ and $-2.6 \sigma_{\text {neut }}$ for $\mathrm{C}-\mathrm{H}$ bonds in TAAM_UR. The corresponding values acquired from the IAM_UR model are equal to $-8.2 \sigma_{\text {neut }}$ and $-11.4 \sigma_{\text {neut }}$ for $\mathrm{O}-\mathrm{H}$ and $\mathrm{C}-\mathrm{H}$ distances. This means that $X-\mathrm{H}$ distances obtained from the IAM_UR model are very much shortened when compared with neutron distances - a common observation in conventional X-ray structure analysis. The transferred model (TAAM_UR) greatly improves the $X-\mathrm{H}$ distances when compared with the average neutron values. All the distance values of the $X-\mathrm{H}$ bonds are presented in Table $\mathrm{S} 2$ of the supplementary material.

The ADPs obtained from spherical atom refinements are usually systematically biased by bonding 
and lone-pair electron densities (Cruickshank, 1956). The introduction of multipolar parameters allows deconvolution of the ADPs from bonding density and improves the reliability of the displacement parameters (Brock et al., 1991; Jelsch et al., 1998). For the TAAM_R model, the values of $U^{i j}$ components for the non-H atoms are lower than those of the IAM_R model. The atomic $U_{\text {eq }}$ values, after the TAAM_R refinement, show a $16 \%$ reduction with respect to the IAM_R model. Hirshfeld's rigid-bond test (Hirshfeld, 1976) shows that there is a $\sim 39 \%$ reduction of differences between the mean-squares displacement amplitude (DMSDA) values, on average. There is only one covalent bond, $\mathrm{C} 4-\mathrm{C} 3$, which has a DMSDA value $\left(1.5 \times 10^{-3} \AA^{2}\right)$ above the Hirshfeld limit $\left(10^{-3} \AA^{2}\right)$. For the IAM_R model there are seven bonds which violate this condition (see Table S3). An ORTEP view of the quercetin molecule for IAM_R and TAAM_R models with the similarity index $S_{12}$ values listed for each non-H atom is shown in Fig. 2. This index, introduced by Whitten \& Spackman (2006), is expressed as $S_{12}=100\left(1-R_{12}\right)$, where $R_{12}$ describes the overlap between probability density functions for the two ADP tensors $\mathbf{U}$ as

$$
R_{12}=\int\left[p_{1}(\mathbf{x}) p_{2}(\mathbf{x})\right]^{1 / 2} d^{3} \mathbf{x}=\frac{2^{3 / 2}\left[\operatorname{det}\left(\mathbf{U}_{1}^{-1} \mathbf{U}_{2}^{-1}\right)\right]^{1 / 4}}{\left[\operatorname{det}\left(\mathbf{U}_{1}^{-1}+\mathbf{U}_{2}^{-1}\right)\right]^{1 / 2}} .
$$

Therefore, the similarity index can be used to describe the percentage difference of two probability density functions. The values of the $S_{12}$ index calculated for the $\mathbf{U}_{1}$ and $\mathbf{U}_{2} \mathrm{ADP}$ tensors obtained from IAM_R and TAAM_R models vary for different atoms in the range $0.52-2.03 \%$. A higher dissimilarity is observed for the $\mathrm{C}$ atoms than for the $\mathrm{O}$ atoms. The average value of the $S_{12}$ index was found to be $1.21 \%$. Comparable values of the $S_{12}$ index for the estimated hydrogen ADPs were noticed by Munshi, Madsen et al. (2008), when those were compared between different methods and with neutron diffraction results.

Although, the $S_{12}$ index can provide information about the dissimilarity of two ADP tensors, it does not indicate the direction of these differences. The qualitative picture of the ADP differences between IAM_R and TAAM_R models was plotted (Fig. 6) using the PEANUT program (Hummel et al., 1990). It is apparent from Fig. 6 that the IAM_R model overestimates the displacement parameters for the $\mathrm{C}$ atoms in the plane of the molecule where covalent bonding occurs. A very small negative difference (underestimation) is however visible in the out-of-plane direction for these atoms. For the $\mathrm{O}$ atoms, the largest overestimation is observed in directions perpendicular to the $\mathrm{C}-\mathrm{O}$ bonds, which can be related to the locations of electron lone pairs. Similar improvements of the ADPs were observed in many studies when the electrondensity parameters were transferred in this fashion (Dittrich $e t$ al., 2005, 2008; Zarychta et al., 2007; Bąk et al., 2009; Dittrich, Weber et al., 2009).

The residual electron-density maps for the final IAM_R and TAAM_R models are shown in Fig. S1 and the crystallographic statistics are given in Table 3. For the IAM_R model the bonding electron density, which was not modelled by the spherical atom model, is clearly seen, especially in the region of the $\mathrm{C}-\mathrm{C}$ aromatic bonds. On the other hand, the same region in the TAAM_R model is almost flat with the highest peak and hole being 0.14 and -0.16 e $\AA^{-3}$ (see Table 3). All the corresponding statistical descriptors are also lower in the TAAM_R model. For example, $R(F)$ decreases significantly from 0.040 to 0.022 .

The statistics for the unrestrained models IAM_UR and TAAM_UR are also provided for comparison (see Table 3). A significant decrease in $R(F)$ from 0.038 (IAM_UR) to 0.022 (TAAM_UR) is observed. The IAM_UR model leads to a very marginally improved $R(F)$ value compared with IAM_R $(0.038$ versus 0.040$)$. This is caused by a better fit of the $\mathrm{X}$-ray data in the unrestrained model which has shortened $X-\mathrm{H}$ distances compared with the model restrained to standard distances from neutron diffraction.

In addition, the accuracy of the TAAM_R model was validated by comparing with the TAAM_THEO_R model. The final refinement statistics listed in Table 3 suggest that the TAAM_R model is equally good or slightly better than the TAAM_THEO_R model. The same $16 \%$ reduction in the $U_{\text {eq }}$ values is observed in the TAAM_THEO_R refinement as it was for the TAAM_R model compared with IAM_R. However, Hirshfeld's (1976) rigid-bond test shows further reduction of the DMSDA values for the TAAM_THEO_R model compared with the IAM_R model. There is a $66 \%$ reduction on average and all the DMSDA values for the TAAM_THEO_R model are below the Hirshfeld limit (Table S3). The ADPs of the non-H atoms for the TAAM_R and the TAAM_THEO_R models were found to be very similar. The $S_{12}$ index calculated for the non-H atom ADPs from these two models was only $0.05 \%$. The PEANUT representation of ADP differences between the TAAM_THEO_R and TAAM_R models is shown in Fig. S2. It appears that the ADPs for the TAAM_THEO_R model are expanded along the covalent bonds, whereas they are contracted in the direction out of the

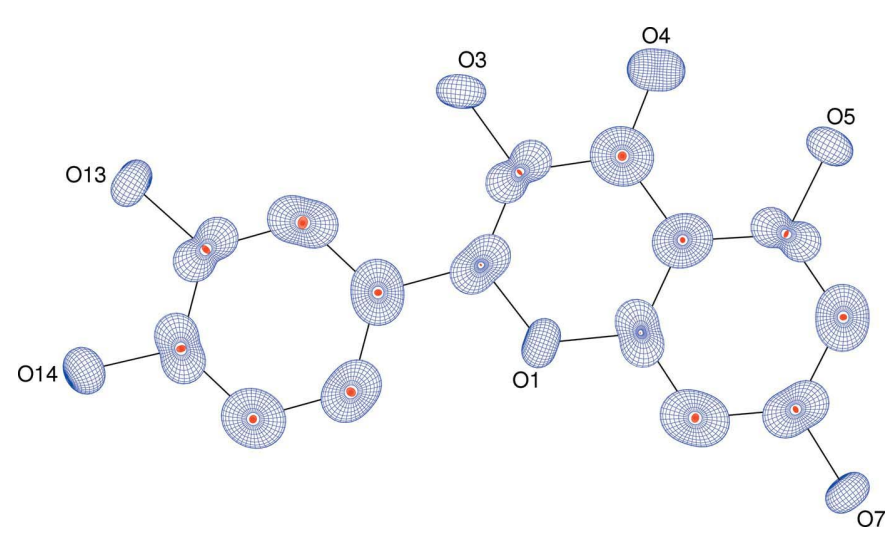

Figure 6

PEANUT (Hummel et al., 1990) representations of the ADP differences between the IAM_R and TAAM_R restrained models. The root meansquare displacement difference surfaces are shown on a scale of 6:15. The positive differences appear in blue, while the negative ones are in red. $\mathrm{H}$ atoms were omitted as their displacement parameters were restrained to those of the carrying atoms. An equivalent orientation to the ORTEP plot was selected. 
molecular plane. The expansion is more prominent for $\mathrm{C}$ atoms while the contraction is more pronounced for $\mathrm{O}$ atoms. This can be related to the slight enhancement of lone pairs and reduction of bonding densities (see §3.4) in the theoretical refinement compared with the experimental database.

\subsection{Charge density analyses}

The deformation electron density and the derived oneelectron properties based on the TAAM_OPT and THEO_OPT models are compared quantitatively. To facilitate a better comparison and to avoid the influence of using different atomic positions, both models were constructed based on the optimized structure of the quercetin monohydrate.

\subsection{Deformation electron densities}

The static deformation electron-density maps of the quercetin molecule are shown in Fig. S3 for both TAAM_OPT and THEO_OPT models (the water molecule is shown in Fig. S4). The maps agree qualitatively. However, the deformation electron-density features are smeared in the TAAM_OPT model. This is even more clearly visible in the difference deformation electron-density map presented in Fig. 7. The most prominent differences are visible in the vicinity of the $\mathrm{O}$ atoms. In the THEO_OPT model $\mathrm{O}$ atoms show enhancement of the electron lone pairs and depletion of the electron

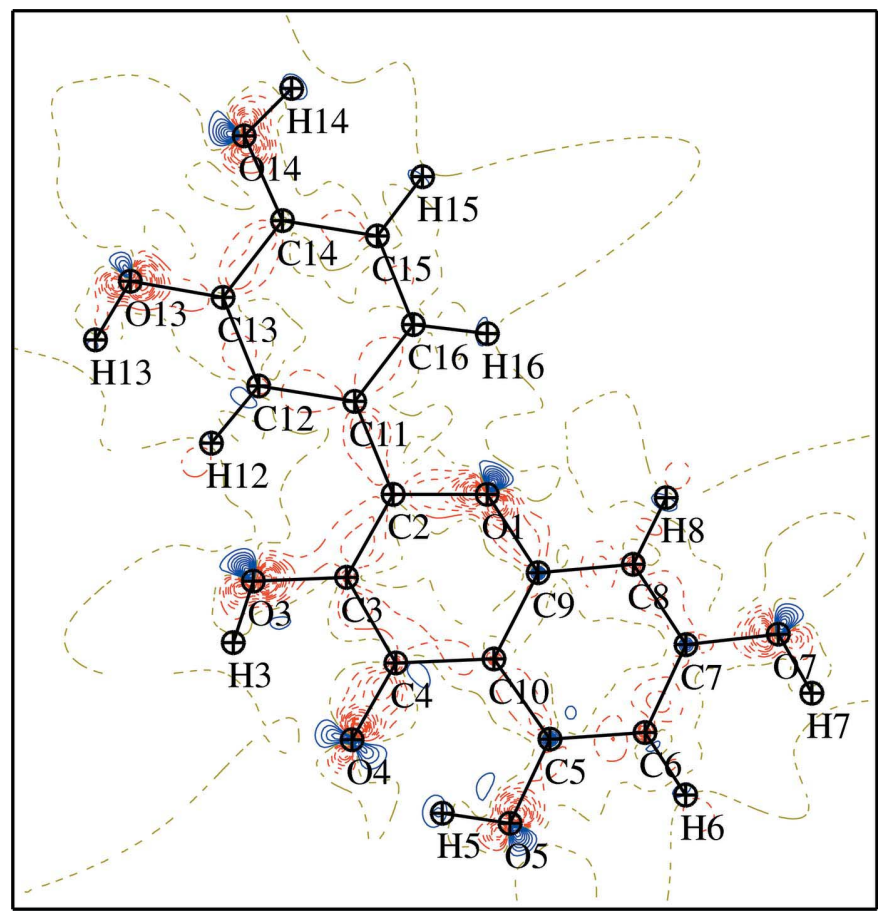

Figure 7

Difference static deformation electron-density map (THEO_OPT TAAM_OPT) models in the plane of the quercetin molecule. Blue solid lines and red dashed lines denote positive and negative contours, respectively. Contour level: \pm 0.05 e $\AA^{-3}$. The zero contours are shown as yellow dashed lines. densities around their nuclei and in the direction of the covalent bonds.

In order to check the quantitative differences between the TAAM_OPT and THEO_OPT models, a statistical analysis was performed on three-dimensional grids containing the deformation electron density of the quercetin molecule. The grids were prepared in the following way. The superposition of the deformation electron density for the parent quercetin molecule (without a water molecule) and all the symmetry equivalents were calculated in the box around the selected quercetin molecule. The average values of the deformation electron density are very close to zero $\left(\sim 10^{-4}\right.$ e $\left.\AA^{-3}\right)$, and the root mean-square deviation (r.m.s.d.) values are very similar

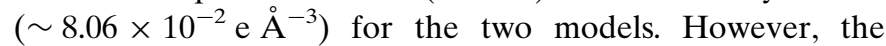
electron density extrema are reduced for the TAAM_OPT model with the minimum and maximum values being -0.343 and $0.867 \mathrm{e}^{-3}$. The corresponding values for the THEO_OPT model are -0.957 and 1.136 e $\AA^{-3}$. The overall (Pearson's) correlation between deformation electron-density grids is very good and the correlation coefficient is equal to 0.957 .

Fig. 8 shows the deformation electron density for the hydroxyl group $\mathrm{O} 3-\mathrm{H} 3$ in the plane bisecting the $\mathrm{C}-\mathrm{O}-\mathrm{H}$ triplet of atoms. This hydroxyl group is the most out-of-plane of the aromatic ring as the dihedral angle $\mathrm{H} 3-\mathrm{O} 3-\mathrm{C} 3-\mathrm{C} 4$ reaches $20.0(1)^{\circ}$. For the THEO_OPT model the electron lone pairs of the $\mathrm{O}$ atom follow the local geometry and the symmetry of the $\mathrm{H} 3-\mathrm{O} 3-\mathrm{C} 3$ plane and not that of the aromatic ring. This justifies the TAAM electron density modelling for hydroxyl groups bound to aromatic rings for which the local axes system is oriented according to the local $\mathrm{C}-\mathrm{O}-\mathrm{H}$ plane. The TAAM_OPT deformation electrondensity map in Fig. 8(a) appears to be slightly smeared and attenuated compared with the THEO_OPT model (Fig. 8b). The electron lone pairs of the $\mathrm{O}$ atom are separated by three contour levels in the THEO_OPT model, whereas for the TAAM_OPT model the lone pairs are separated by only one contour level. In the previous ELMAM database for proteins (Zarychta et al., 2007) the two lone pairs appeared to be merged, which was attributed to some resonance effect with the aromatic ring of tyrosine. In their study Farrugia et al. (2009) also observed that the electron lone pairs of similar O atoms are almost merged. According to those authors, an $s p^{3}$ description seems most appropriate for the hybridization of such hydroxyl atoms, but the ellipticity profile along the $\mathrm{C}-\mathrm{O}$ bond suggests some $\pi$ character, implying partial $s p^{2}$ hybridization. The deformation electron density of the water molecule $(\mathrm{H} 1 W-\mathrm{O} 1 W-\mathrm{H} 2 W)$ obtained from the THEO_OPT model is also shown for comparison (Fig. 8c). For this $\mathrm{Osp}^{3}$ atom the lone pairs are more separated, by up to seven contour levels.

\subsection{Topology of covalent bonds}

The topological description of the electron density at the bond-critical points (BCPs) in quercetin monohydrate for TAAM_OPT and THEO_OPT models is presented in Table 
S4. The two models agree well. The coefficients of determination $\left(R^{2}\right)$ obtained between $\rho\left(\mathbf{r}_{\mathrm{CP}}\right), \nabla^{2} \rho\left(\mathbf{r}_{\mathrm{CP}}\right)$ and distances to BCPs $\left(d_{A \cdots \mathrm{CP}}, d_{B \cdots \mathrm{CP}}\right)$ are in the range $0.955-0.996$ (see plots $a, b, c$ and $d$ in Fig. S5). All the plots were made using gnuplot4.2 (Williams et al., 2009). For the TAAM_OPT model systematically larger values of $\rho\left(\mathbf{r}_{\mathrm{CP}}\right)$ and lower (more negative) values of $\nabla^{2} \rho\left(\mathbf{r}_{\mathrm{CP}}\right)$ were noted. The largest differences in $\rho\left(\mathbf{r}_{\mathrm{CP}}\right)$ and $\nabla^{2} \rho\left(\mathbf{r}_{\mathrm{CP}}\right)$ values were noted for the $\mathrm{O} 4-\mathrm{C} 4$ bond $\left(0.23 \mathrm{e} \AA^{-3}\right.$ and $\left.-5.75 \mathrm{e} \AA^{-5}\right)$ in the quercetin molecule and for the $\mathrm{O} 1 W-\mathrm{H} 2 W$ bond $\left(0.10 \mathrm{e} \AA^{-3}\right.$ and $\left.-9.14 \mathrm{e}^{-5}\right)$ in the water molecule. The high discrepancy of the $\rho\left(\mathbf{r}_{\mathrm{CP}}\right)$ and $\nabla^{2} \rho\left(\mathbf{r}_{\mathrm{CP}}\right)$ values for the carbonyl group may be connected to the higher uncertainty on the multipolar parameters of the $\mathrm{O} 4$ atom in the TAAM_OPT model. A smaller number of atoms were indeed available to build the average values in the databank for this aromatic carbonyl O-atom type. The second maximum discrepancy for non- $\mathrm{H}$ atoms in $\rho\left(\mathbf{r}_{\mathrm{CP}}\right)$ and $\nabla^{2} \rho\left(\mathbf{r}_{\mathrm{CP}}\right)$ values between two models is observed for the $\mathrm{O} 1-\mathrm{C} 2$ bond $\left(0.15 \mathrm{e} \AA^{-3}\right.$ and $\left.-4.69 \mathrm{e} \AA^{-5}\right)$. The maximum difference in the position of the $\mathrm{BCP}$ is registered for the $\mathrm{C} 8-\mathrm{C} 9$ bond $(0.028 \AA)$. The average differences between the TAAM_OPT and THEO_OPT models do not exceed $0.07 \mathrm{e}^{-3}$ and $-3.47 \mathrm{e} \AA^{-5}$, and 0.006 and $-0.006 \AA$ for $\rho\left(\mathbf{r}_{\mathrm{CP}}\right), \nabla^{2} \rho\left(\mathbf{r}_{\mathrm{CP}}\right)$, $d_{A \cdots \mathrm{CP}}$ and $d_{B \cdots \mathrm{CP}}$. In their study on the bergenin molecule, which has a similar size to quercetin monohydrate, Dittrich, Weber et al. (2009) noted similar discrepancies of $\rho\left(\mathbf{r}_{\mathrm{CP}}\right)$ and $\nabla^{2} \rho\left(\mathbf{r}_{\mathrm{CP}}\right)$ when the values were compared between the invariom model and theoretical calculations. Additionally, we have analysed the relative agreement between the models in terms of the reliability factor $R(p)$ of property $p$ defined as

$$
R(p)=\sum\left|p_{\text {TAAM_OPT }}-p_{\text {THEO_OPT }}\right| / \sum\left|p_{\text {TAAM_OPT }}\right| .
$$

The values of $R(p)$ obtained were: $R\left(\rho\left(\mathbf{r}_{\mathrm{CP}}\right)\right)=0.034$ and $R\left(\nabla^{2} \rho\left(\mathbf{r}_{\mathrm{CP}}\right)\right)=0.164$, for the electron density and its Laplacian, respectively.

\subsection{Topology of intra- and intermolecular contacts}

Quantitative analysis of intra- and intermolecular interactions were performed in terms of the topology of the electron density. The interactions are listed in Table 6. As noted from the IAM_R model, the quercetin molecule has two intramolecular short contacts: $\mathrm{O} 5-\mathrm{H} 5 \cdots \mathrm{O} 4$ and $\mathrm{C} 12-$ $\mathrm{H} 12 \cdots \mathrm{O} 3$ with $\mathrm{H} \cdots \mathrm{O}=1.691$ and $2.097 \AA$. All intra- and intermolecular interactions of the type $\mathrm{O}-\mathrm{H} \cdots \mathrm{O}$ satisfy the first four of Koch and Popelier's (KP; Koch \& Popelier, 1995; Popelier, 2000) criteria and therefore can be classified as hydrogen bonds. Based on the fourth of KP's criteria, the longest $\mathrm{C} 12-\mathrm{H} 12 \cdots \mathrm{O} 1 W$ contact $\left(d_{\mathrm{H} \cdots \mathrm{O}}=2.723 \AA\right)$ was found to be a van der Waals type. However, all other $\mathrm{C}-$ $\mathrm{H} \cdots \mathrm{O}$ contacts are found to satisfy the conditions of a hydrogen bond. The values of $\rho\left(\mathbf{r}_{\mathrm{CP}}\right), \nabla^{2} \rho\left(\mathbf{r}_{\mathrm{CP}}\right), G\left(\mathbf{r}_{\mathrm{CP}}\right)$ and $V\left(\mathbf{r}_{\mathrm{CP}}\right)$ for the $\mathrm{H} \cdots \mathrm{O}$ contacts are within good agreement with similar contacts reported in the literature (Espinosa et al., 2002; Mallinson et al., 2003; Munshi \& Guru Row, 2005b; Dominiak et al., 2006; Mata et al., 2010). The exponential

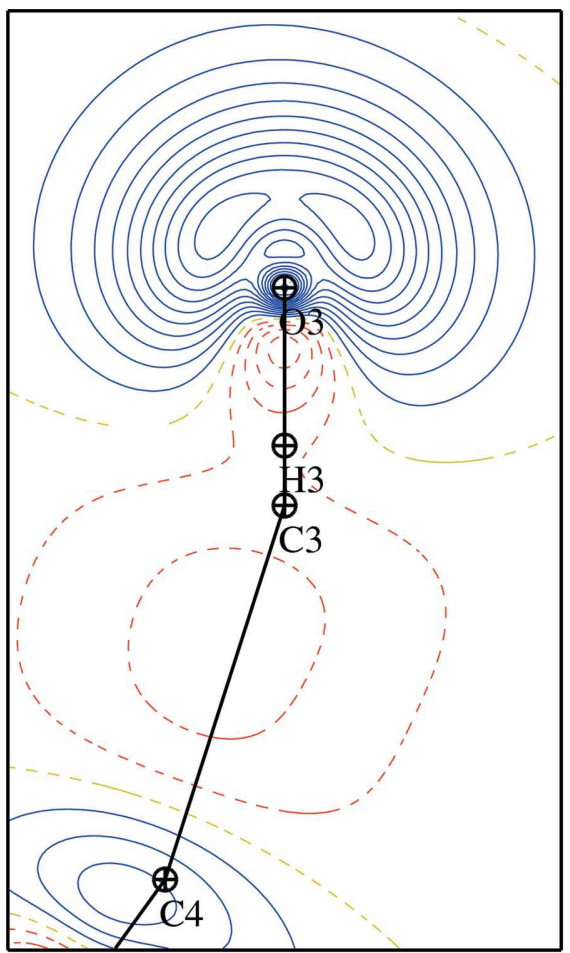

(a)

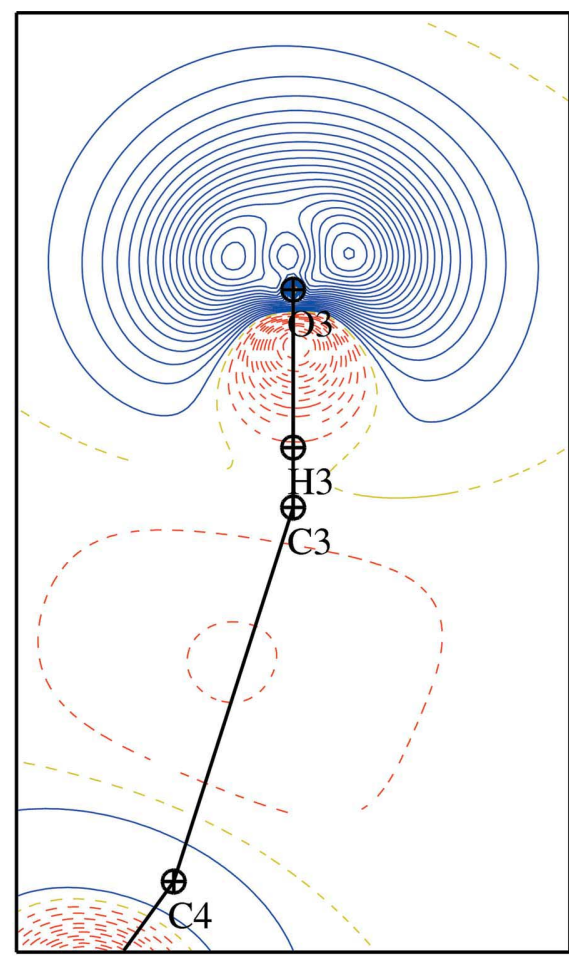

(b)

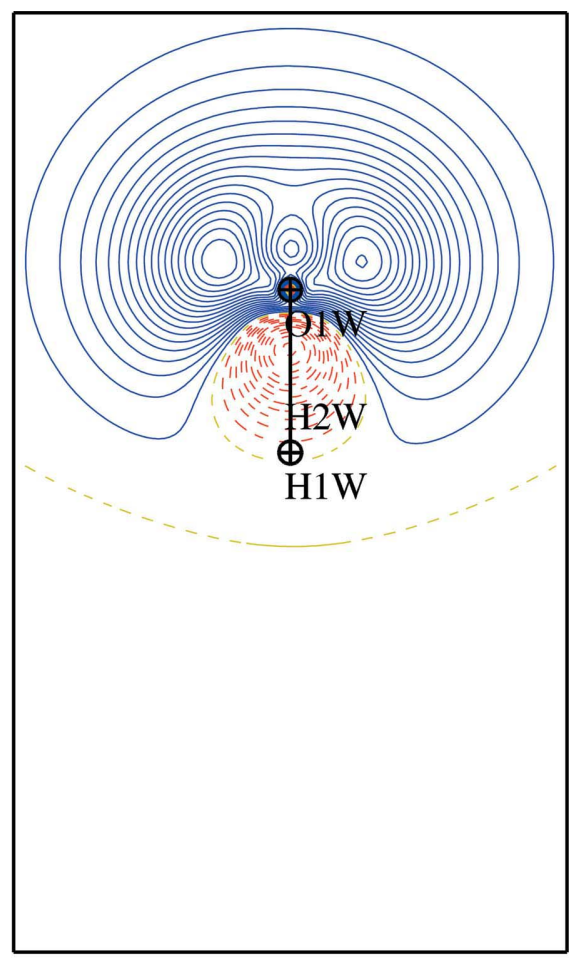

(c)

Figure 8

Static deformation electron-density maps in the plane of the lone pairs of O3 and O1W atoms. Maps show the deformation electron density in the region of the hydroxyl group for $(a)$ TAAM_OPT and $(b)$ THEO_OPT models, and of the water molecule for $(c)$ THEO_OPT. Blue solid lines and red dashed

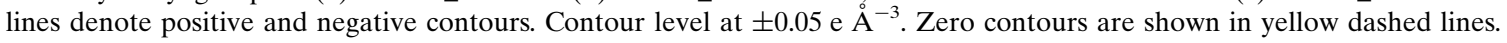


Table 6

Topological properties of the electron density for the intra- and intermolecular contacts in the quercetin monohydrate for the TAAM_OPT (first entry) and THEO_OPT (second entry in italics) models.

The distances are given in $\AA$, total electron density $\rho\left(\mathbf{r}_{\mathrm{CP}}\right)$ in e $\AA^{-3}$, Laplacian $\nabla^{2} \rho\left(\mathbf{r}_{\mathrm{CP}}\right)$ in e $\AA^{-5}$. The kinetic energy density $G\left(\mathbf{r}_{\mathrm{CP}}\right)$ and potential energy density $V\left(\mathbf{r}_{\mathrm{CP}}\right)$ (Abramov, 1997) are in $\mathrm{kJ} \mathrm{mol}^{-1} \mathrm{bohr}^{-3}$. The $d_{A B}$ values are the same for both models as these are based on the optimized geometry. Contacts with common $\mathrm{CP}$ are marked with '*'.

\begin{tabular}{|c|c|c|c|c|c|c|c|c|c|}
\hline Contacts & $d_{A B}$ & $d_{A \cdots \mathrm{CP}}$ & $d_{B \cdots \mathrm{CP}}$ & $\Delta r_{D}-\Delta r_{A}$ & $\Delta r_{D}+\Delta r_{A}$ & $\rho\left(\mathbf{r}_{\mathrm{CP}}\right)$ & $\nabla^{2} \rho$ & $G\left(\mathbf{r}_{\mathrm{CP}}\right)$ & $V\left(\mathbf{r}_{\mathrm{CP}}\right)$ \\
\hline \multirow[t]{2}{*}{$\mathrm{O} 3-\mathrm{H} 3 \cdots \mathrm{O} 4^{\mathrm{i}}$} & 1.8127 & 0.6531 & 1.1690 & 0.1759 & 0.9179 & 0.2287 & 1.75 & 58.5 & -69.4 \\
\hline & & 0.6377 & 1.1774 & 0.1997 & 0.9249 & 0.2267 & 2.30 & 68.1 & -73.6 \\
\hline $\mathrm{O} 5-\mathrm{H} 5 \cdots \mathrm{O} 4^{\mathrm{ii}}$ & 1.6907 & 0.5644 & 1.1312 & 0.2268 & 1.0444 & 0.3185 & 2.00 & 82.7 & -111.1 \\
\hline \multirow[t]{2}{*}{$\mathrm{O} 7-\mathrm{H} 7 \cdots \mathrm{O} 13^{\mathrm{iii}}$} & 1.7736 & 0.6095 & 1.1645 & 0.2150 & 0.9660 & 0.2865 & 1.06 & 58.2 & -87.5 \\
\hline & & 0.6151 & 1.1587 & 0.2036 & 0.9662 & 0.2682 & 1.51 & 62.3 & -83.5 \\
\hline \multirow[t]{2}{*}{$\mathrm{O} 13-\mathrm{H} 13 \cdots \mathrm{O} 1 W^{\mathrm{iv}}$} & 1.7005 & 0.5638 & 1.1371 & 0.2333 & 1.0391 & 0.3346 & 1.11 & 70.6 & -111.0 \\
\hline & & 0.5742 & 1.1266 & 0.2124 & 1.0392 & 0.3227 & 1.73 & 78.9 & -110.7 \\
\hline \multirow{2}{*}{$\mathrm{O} 1 W-\mathrm{H} 2 W \cdots \mathrm{O} 4^{\mathrm{i}}$} & 1.8803 & 0.6870 & 1.1946 & 0.1676 & 0.8584 & 0.2053 & 1.25 & 45.0 & -56.0 \\
\hline & & 0.6766 & 1.2047 & 0.1881 & 0.8587 & 0.2096 & 1.50 & 50.3 & -59.9 \\
\hline \multirow{2}{*}{$\mathrm{O} 1 W-\mathrm{H} 1 W \cdots \mathrm{O} 5^{\mathrm{vi}}$} & 2.1263 & 0.8094 & 1.3221 & 0.1727 & 0.6085 & 0.1248 & 1.11 & 29.9 & -29.6 \\
\hline & & 0.8114 & 1.3198 & 0.1684 & 0.6088 & 0.1232 & 1.16 & 30.6 & -29.6 \\
\hline \multirow{2}{*}{$\mathrm{O} 1 W-\mathrm{H} 1 \mathrm{~W} \cdots \mathrm{O} 5^{\mathrm{vii}}$} & 2.3628 & 0.9482 & 1.4246 & 0.1364 & 0.3672 & 0.0635 & 0.84 & 18.4 & -13.9 \\
\hline & & 0.9484 & 1.4253 & 0.1369 & 0.3663 & 0.0632 & 0.87 & 18.9 & -14.2 \\
\hline $\mathrm{C} 6-\mathrm{H} 6 \cdots \mathrm{O} 13^{\mathrm{iii}}$ & 2.5612 & 1.0664 & 1.4957 & 0.0893 & 0.1779 & 0.0454 & 0.75 & 15.4 & -10.4 \\
\hline $\mathrm{C} 12-\mathrm{H} 12 \cdots \mathrm{O}^{\mathrm{ii}}$ & & 0.8606 & 1.2538 & 0.0532 & 0.6256 & 0.1433 & 2.07 & 49.8 & -43.3 \\
\hline $\mathrm{C} 12-\mathrm{H} 12 \cdots \mathrm{O} 1 W^{\mathrm{iv}}$ & 2.7229 & 1.1467 & 1.6084 & 0.1217 & -0.0151 & 0.0343 & 0.60 & 12.0 & -7.7 \\
\hline & & 1.1612 & 1.5856 & 0.0844 & -0.0068 & 0.0390 & 0.58 & 11.9 & -8.1 \\
\hline $\mathrm{C} 15-\mathrm{H} 15 \cdots \mathrm{O}^{\mathrm{v}}$ & 2.6588 & 1.1067 & 1.5538 & 0.1071 & 0.0795 & 0.0365 & 0.62 & 12.5 & -8.1 \\
\hline & & 1.1607 & 1.5396 & 0.0389 & 0.0397 & 0.0408 & 0.61 & 12.6 & -8.6 \\
\hline $\mathrm{O} 5 \cdots \mathrm{O} 5^{\mathrm{ix}}$ & 3.0075 & 1.5063 & 1.5013 & -0.0050 & 0.0724 & 0.0452 & 0.78 & 15.9 & -10.7 \\
\hline & & 1.5073 & 1.5004 & -0.0069 & 0.0723 & 0.0456 & 0.75 & 15.4 & -10.4 \\
\hline $\mathrm{O} 7 \cdots \mathrm{O} 14^{\mathrm{iii}}$ & 2.8821 & 1.4683 & 1.4287 & -0.0396 & 0.1830 & 0.0628 & 1.16 & 24.2 & -16.7 \\
\hline & & 1.4814 & 1.4131 & -0.0683 & 0.1855 & 0.0632 & 1.14 & 23.8 & -16.6 \\
\hline $\mathrm{O} 14 \cdots \mathrm{O} 14^{\mathrm{x}}$ & 3.1599 & 1.5411 & 1.6206 & 0.0795 & -0.0817 & 0.0333 & 0.57 & 11.4 & -7.3 \\
\hline & & 1.5465 & 1.6162 & 0.0697 & -0.0827 & 0.0357 & 0.61 & 12.3 & -7.9 \\
\hline $\mathrm{O} 1 \cdots \mathrm{C} 7^{\mathrm{iv}}$ & 3.2665 & 1.6188 & 1.6741 & -0.2547 & 0.0971 & 0.0386 & 0.49 & 10.3 & -7.2 \\
\hline & & 1.6401 & 1.6677 & -0.2824 & 0.0822 & 0.0357 & 0.47 & 9.7 & -6.7 \\
\hline $\mathrm{O} 1 \cdots \mathrm{C} 12^{* \mathrm{xi}}$ & 3.3900 & 1.6516 & 1.7406 & -0.2210 & -0.0022 & 0.0361 & 0.44 & 9.2 & -6.5 \\
\hline $\mathrm{O} 7 \cdots \mathrm{C} 9^{* \mathrm{xi}}$ & 3.4940 & 1.6923 & 1.8146 & -0.1877 & -0.1169 & & & & \\
\hline $\mathrm{O} 7 \ldots \mathrm{C} 13 * \mathrm{viii}$ & 32668 & $\begin{array}{l}1.6831 \\
1.5764\end{array}$ & $\begin{array}{l}1.8770 \\
1.7104\end{array}$ & $\begin{array}{l}-0.1161 \\
-0.1760\end{array}$ & $\begin{array}{r}-0.1701 \\
01032\end{array}$ & 0.0418 & 0.55 & 115 & -81 \\
\hline & .2000 & 1.5816 & 1.7059 & -0.1857 & 0.1025 & 0.0400 & 0.53 & 11.1 & -0.1 \\
\hline $\mathrm{O} 7 \cdots \mathrm{C} 14 * \mathrm{viii}$ & 3.2946 & 1.5764 & 1.8638 & -0.0226 & -0.0502 & & & & \\
\hline & & 1.5816 & 1.8604 & -0.0312 & -0.0520 & & & & \\
\hline $\mathrm{O} 13 \cdots \mathrm{C} 6^{* \mathrm{xii}}$ & 3.2836 & 1.5385 & 1.8879 & 0.0394 & -0.0364 & 0.0492 & 0.65 & 13.9 & -10.0 \\
\hline & & 1.5501 & 1.8090 & -0.0511 & 0.0309 & 0.0468 & 0.62 & 13.2 & -9.4 \\
\hline $\mathrm{O} 13 \cdots \mathrm{C} 77^{* \mathrm{xi}}$ & 3.1600 & 1.5385 & 1.6424 & -0.2061 & 0.2091 & & & & \\
\hline & & 1.5501 & 1.6756 & -0.1845 & 0.1643 & & & & \\
\hline $\mathrm{O} 13 \cdots \mathrm{C} 11^{\text {iv }}$ & 3.3591 & 1.6750 & 1.7397 & -0.2453 & -0.0247 & 0.0339 & 0.43 & 8.9 & -6.1 \\
\hline & & 1.6557 & 1.7226 & -0.2431 & 0.0117 & 0.0319 & 0.43 & 8.8 & -5.9 \\
\hline $\mathrm{O} 14 \cdots \mathrm{C} 16^{\mathrm{iv}}$ & 3.4828 & 1.7520 & 1.7652 & -0.2968 & -0.1272 & 0.0255 & 0.32 & 6.5 & -4.3 \\
\hline & & 1.7027 & 1.7809 & -0.2318 & -0.0936 & 0.0246 & 0.32 & 6.5 & -4.2 \\
\hline $\mathrm{C} 3 \cdots \mathrm{C} 5^{* \mathrm{iv}}$ & 3.3231 & 1.6690 & 1.6813 & 0.0123 & 0.3497 & 0.0427 & 0.47 & 10.2 & -7.5 \\
\hline & & 1.7061 & 1.6822 & -0.0239 & 0.3117 & 0.0415 & 0.47 & 10.1 & -7.4 \\
\hline $\mathrm{C} 3 \cdots \mathrm{C} 6^{* \mathrm{iv}}$ & 3.6068 & 1.6690 & 2.0629 & 0.3939 & -0.0319 & & & & \\
\hline & & 1.7061 & 1.9763 & 0.2702 & 0.0176 & & & & \\
\hline $\mathrm{C} 6 \cdots \mathrm{C} 10^{\mathrm{xi}}$ & 3.5131 & 1.7346 & 1.7823 & -0.0477 & 0.1831 & 0.0300 & 0.35 & 7.3 & -5.0 \\
\hline & & 1.7345 & 1.7823 & -0.0478 & 0.1832 & 0.0339 & 0.38 & 8.0 & -5.7 \\
\hline $\mathrm{C} 8 \cdots \mathrm{C} 11^{* \mathrm{xi}}$ & 3.4765 & 1.9194 & 1.6781 & 0.2413 & 0.1025 & 0.0448 & 0.49 & 10.7 & -8.0 \\
\hline & & 1.8774 & 1.6711 & 0.2063 & 0.1515 & 0.0420 & 0.48 & 10.3 & -7.5 \\
\hline
\end{tabular}


research papers

Table 6 (continued)

\begin{tabular}{|c|c|c|c|c|c|c|c|c|c|}
\hline Contacts & $d_{A B}$ & $d_{A \cdots \mathrm{CP}}$ & $d_{B \cdots \mathrm{CP}}$ & $\Delta r_{D}-\Delta r_{A}$ & $\Delta r_{D}+\Delta r_{A}$ & $\rho\left(\mathbf{r}_{\mathrm{CP}}\right)$ & $\nabla^{2} \rho$ & $G\left(\mathbf{r}_{\mathrm{CP}}\right)$ & $V\left(\mathbf{r}_{\mathrm{CP}}\right)$ \\
\hline \multirow[t]{2}{*}{$\mathrm{C} 9 \cdots \mathrm{C} 11^{* \mathrm{xi}}$} & 3.3120 & 1.6936 & 1.6781 & -0.0155 & 0.3283 & & & & \\
\hline & & 1.7278 & 1.6711 & -0.0567 & 0.3011 & & & & \\
\hline H8 $\cdots H 15^{\mathrm{xiii}}$ & 2.1165 & 1.0471 & 1.0739 & 0.0268 & 0.2790 & 0.0492 & 0.78 & 16.2 & -11.2 \\
\hline \multirow[t]{2}{*}{$\mathrm{H} 16 \cdots \mathrm{H} 15^{\mathrm{xiii}}$} & 2.5772 & 1.2414 & 1.3949 & 0.1535 & -0.2363 & 0.0240 & 0.28 & 5.7 & -3.8 \\
\hline & & 1.1844 & 1.4213 & 0.2369 & -0.2057 & 0.0227 & 0.30 & 6.0 & -3.9 \\
\hline
\end{tabular}

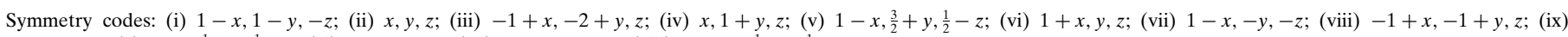
$-x,-y,-z$; (x) $2-x, \frac{1}{2}+y, \frac{1}{2}-z$; (xi) $x,-1+y, z$; (xii) $1+x, 1+y, z$; (xiii) $1-x,-\frac{1}{2}+y, \frac{1}{2}-z$.

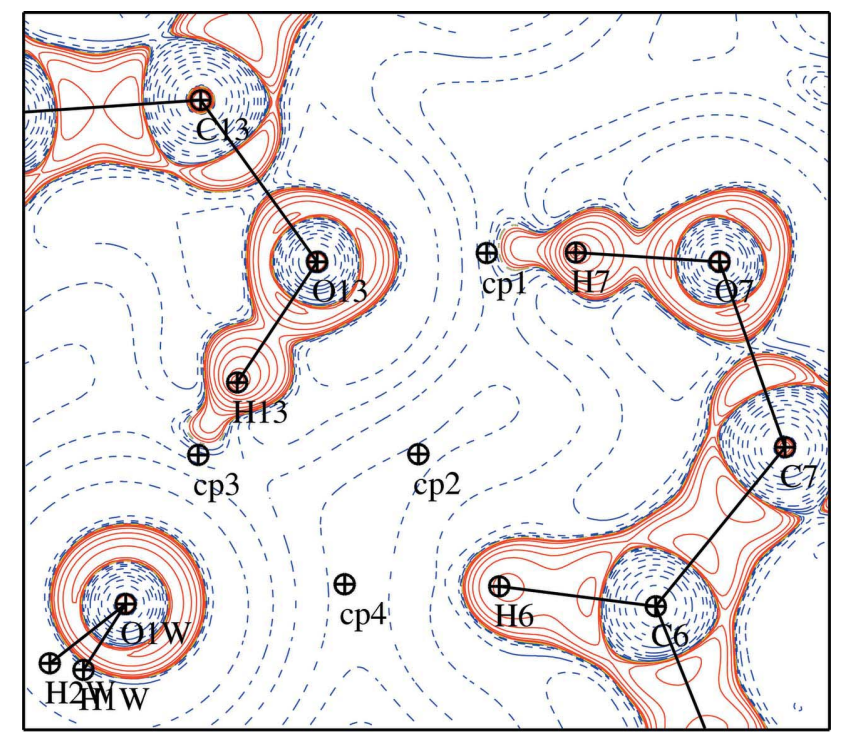

(a)

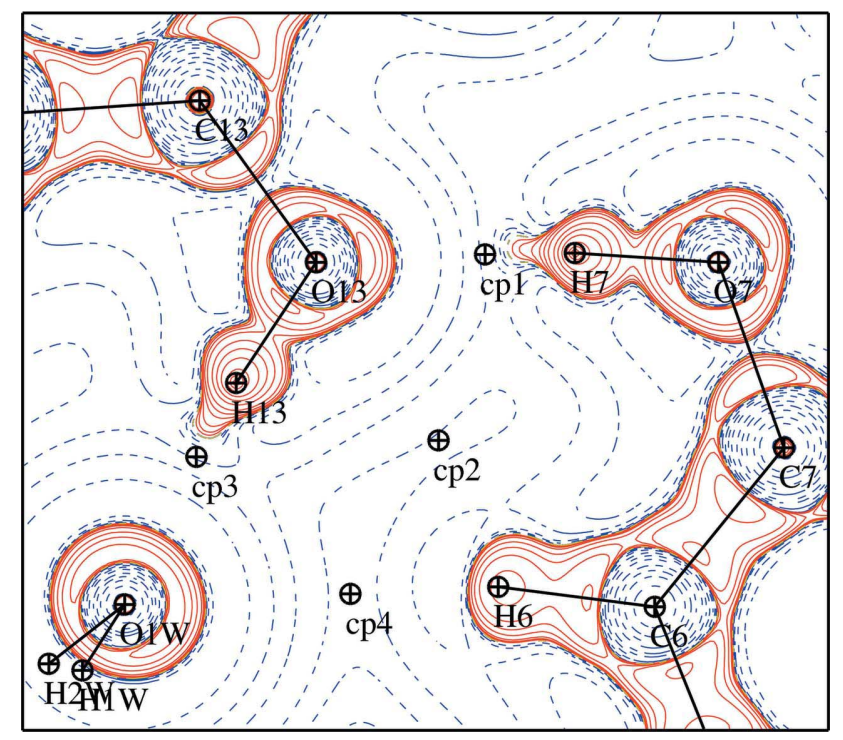

(b)

Figure 9

Laplacian $\left[\nabla^{2} \rho(\mathbf{r})\right]$ maps of representative $\mathrm{C}-\mathrm{H} \cdots \mathrm{O}$ and $\mathrm{O}-\mathrm{H} \cdots \mathrm{O}$ hydrogen bonds from (a) TAAM_OPT and $(b)$ THEO_OPT models. Blue (dashed) and red (solid) lines represent positive and negative values. Contours are drawn at $\pm 2^{m} \times 10^{n} \mathrm{e}^{-5}(m=1,2,3 ; n=-3,-2 \ldots)$ levels. Maps are plotted in the plane containing atoms $\mathrm{O} 13, \mathrm{O} 7$ and $\mathrm{O} 1 W$. dependence of $\rho\left(\mathbf{r}_{\mathrm{CP}}\right), G\left(\mathbf{r}_{\mathrm{CP}}\right)$ and $V\left(\mathbf{r}_{\mathrm{CP}}\right)$ on $R_{i j}$ observed in those reports is also observed here. The coefficients of determination $R^{2}$ obtained between $\rho\left(\mathbf{r}_{\mathrm{CP}}\right), G\left(\mathbf{r}_{\mathrm{CP}}\right), V\left(\mathbf{r}_{\mathrm{CP}}\right)$ and $R_{i j}$ range from 0.926 to 0.993 (Fig. S6).

The six strongest hydrogen bonds, with $\mathrm{H} \cdots \mathrm{O}<1.9 \AA$ (Table 6), exhibit increased covalent contributions $\left[\left|V\left(\mathbf{r}_{\mathrm{CP}}\right)\right|>\right.$ $G\left(\mathbf{r}_{\mathrm{CP}}\right)$ ] and can be associated with region II (transit closed shell) as classified by Espinosa et al. (2002). The corresponding maps show significant polarization of the Laplacian of the electron density of the $\mathrm{H}$ atoms towards the acceptor atoms, which is pronounced in the TAAM_OPT model (Fig. 9). These characteristic features of stronger hydrogen bonds were also observed in other cases when the $\mathrm{H}$ atoms were modelled with quadrupolar functions (Overgaard et al., 2001; Roversi \& Destro, 2004; Destro et al., 2005). The other H. .O bonds $\left(d_{\mathrm{H} \cdots \mathrm{O}}>2.0 \AA\right)$ fall into region I, denoting pure closed-shell interactions.

Numerous $\pi \cdots \pi$ interactions between the aromatic rings of neighbouring quercetin molecules in the crystal lattice were observed. These $\pi \cdots \pi$ interactions include contacts of the $\mathrm{O} \cdots \mathrm{C}$ and $\mathrm{C} \cdots \mathrm{C}$ type with separations ranging from 3.2 to $3.6 \AA$. The values of $\rho\left(\mathbf{r}_{\mathrm{CP}}\right)$ vary in the range $0.025-$

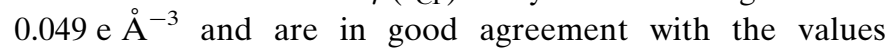
reported in the literature (Espinosa et al., 2002; Mallinson et al., 2003; Munshi \& Guru Row, 2005b; Dominiak et al., 2006; Mata et al., 2010). Some of the contacts share a common CP (marked with an asterisk, see Table 6). One of such interactions is plotted in Fig. 10, which shows that the $\mathrm{C} 11$ atom essentially interacts with the $\pi$ electrons of the $\mathrm{C} 8-\mathrm{C} 9$ bond. A similar scenario was also observed in a recent study by Munshi et al. (2010). Additionally, there are three O..O contacts and two $\mathrm{H} \cdots \mathrm{H}$ short contacts (see Table 6). The $\mathrm{H} 8 \cdot \mathrm{H} 15$ and $\mathrm{H} 15 \cdots \mathrm{H} 16$ contacts with relative distances of 2.1165 and $2.5772 \AA$ form a dimer (symmetry: $\left.1-x,-\frac{1}{2}+y, \frac{1}{2}-z\right)$. An atomic interpenetration was noticed for the H8...H15 contact.

Although Hirshfeld surface analysis suggests that there is $13 \% \mathrm{C} \cdot \mathrm{H}$ contacts in this structure, no BCPs were found for such contacts from the topological analysis based on Bader's QTAIM approach. However, Hirshfeld surface analysis for the remaining contacts is comparable with the topological analysis. In this context it is to be noted that the analyses may not necessarily be correlated as those two approaches are based on different partitioning schemes. Moreover, Hirshfeld surface analysis is performed based on the spherical atom model while Bader's QTAIM is based on an aspherical 
Table 7

Electrostatic interaction energies $\left(\mathrm{kJ} \mathrm{mol}^{-1}\right)$ between interacting pairs of molecules shown for the TAAM_OPT and THEO_OPT models.

\begin{tabular}{|c|c|c|c|c|}
\hline Pair & Symmetry & TAAM_OPT & THEO_OPT & Shortest contact \\
\hline$A$ & $-x,-y,-z$ & 3 & 4 & $\mathrm{O} 5 \cdots \mathrm{O} 5$ \\
\hline$B$ & $\begin{array}{l}1-x, \frac{1}{2}+y, \frac{1}{2}-z \\
1-x,-\frac{1}{2}+y, \frac{1}{2}-z\end{array}$ & -5 & -5 & H8 $\cdots$ H15 \\
\hline C & $\begin{array}{l}1+x, 1+y, z \\
-1+x,-1+y, z\end{array}$ & -12 & -13 & $\mathrm{O} 13 \cdots \mathrm{C} 7$ \\
\hline$D$ & $\begin{array}{l}2-x, \frac{1}{2}+y, \frac{1}{2}-z \\
2-x,-\frac{1}{2}+y, \frac{1}{2}-z\end{array}$ & -19 & -13 & 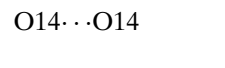 \\
\hline$E$ & $\begin{array}{l}x, 1+y, z \\
x,-1+y, z\end{array}$ & -23 & -28 & $\mathrm{O} 1 \cdots \mathrm{C} 7$ \\
\hline$F$ & $\begin{array}{l}1-x, \frac{3}{2}+y, \frac{1}{2}-z \\
1-x,-\frac{3}{2}+y, \frac{1}{2}-z\end{array}$ & -48 & -40 & $\mathrm{O} 14-\mathrm{H} 14 \cdots \mathrm{O} 7$ \\
\hline$G$ & $\begin{array}{l}1+x, 2+y, z \\
-1+x,-2+y, z\end{array}$ & -69 & -59 & $\mathrm{O} 7-\mathrm{H} 7 \cdots \mathrm{O} 13$ \\
\hline$H$ & $1-x, 1-y,-z$ & -77 & -90 & $\mathrm{O} 3-\mathrm{H} 3 \cdots \mathrm{O} 4$ \\
\hline$I$ & $1-x,-y,-z$ & -12 & -13 & $\mathrm{O} 1 W-\mathrm{H} 1 W \cdots \mathrm{O} 5$ \\
\hline$J$ & $-1+x,-1+y, z$ & -14 & -13 & $\mathrm{C} 6-\mathrm{H} 6 \cdots \mathrm{O} 1 W$ \\
\hline$K$ & $-1+x, y, z$ & -20 & -21 & $\mathrm{O} 1 W-\mathrm{H} 1 W \cdots \mathrm{O} 5$ \\
\hline$L$ & $1-x, 1-y,-z$ & -31 & -40 & $\mathrm{O} 1 W-\mathrm{H} 2 W \cdots \mathrm{O} 4$ \\
\hline$M$ & $x, 1+y, z$ & -79 & -72 & $\mathrm{O} 13-\mathrm{H} 13 \cdots \mathrm{O} 1 \mathrm{~W}$ \\
\hline Total & & -291 & -281 & \\
\hline
\end{tabular}

All 19 crystal contacts are presented. The duplicate contacts are given as the second entry in the symmetry column. Pairs marked by $A-H$ and $I-M$ letters denote quercetin...quercetin and quercetin...water interactions. The dimers are ordered with increasing electrostatic interaction energy. The sum over all interaction contacts is also given, with a weight of $\frac{1}{2}$ for the involutional symmetry dimers (non duplicates).

multipolar model. Differences between these two approaches are highlighted in a recent article by Spackman \& Jayatilaka (2009).

For the TAAM_OPT and THEO_OPT models the topological properties of the electron density of intra- and intermolecular interactions are found to agree well. The reliability factors and $R(p)$ values were 0.048 and 0.131 for $\rho\left(\mathbf{r}_{\mathrm{CP}}\right)$ and $\nabla^{2} \rho\left(\mathbf{r}_{\mathrm{CP}}\right)$. These values do not deviate much from those previously calculated for the covalent bonds. The correlation between the two models as shown in Fig. S7 for $\rho\left(\mathbf{r}_{\mathrm{CP}}\right)$, $\nabla^{2} \rho\left(\mathbf{r}_{\mathrm{CP}}\right), d_{A} \cdots_{\mathrm{CP}}$ and $d_{B} \cdots_{\mathrm{CP}}$ confirms that the models are in good agreement. The lowest determination coefficient $\left(R^{2}=\right.$ $0.918)$ was noticed for $\nabla^{2} \rho\left(\mathbf{r}_{\mathrm{CP}}\right)$. The largest discrepancies in $\rho\left(\mathbf{r}_{\mathrm{CP}}\right)$ and $\nabla^{2} \rho\left(\mathbf{r}_{\mathrm{CP}}\right)$ values are observed for the six strongest hydrogen bonds $\left(d_{\mathrm{H} \cdots \mathrm{O}}<1.9 \AA\right)$. The greatest differences between THEO_OPT and TAAM_OPT models are

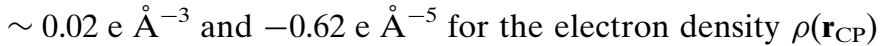
and its Laplacian $\nabla^{2} \rho\left(\mathbf{r}_{\mathrm{CP}}\right)$. These large deviations, especially visible for the Laplacian, can be attributed to an insufficient basis set used for the theoretical calculations to properly describe the large polarization in the case of strong hydrogen bonds (Overgaard et al., 2001). This can also be due to difficulties in both theory and experiment in describing the transit closed-shell interactions. If the six strong hydrogen bonds are omitted, the correlation increases and the reliability $R\left(\nabla^{2} \rho\left(\mathbf{r}_{\mathrm{CP}}\right)\right)$ improves from 0.131 to 0.040 .

Additionally, we have evaluated and compared the values of $\rho\left(\mathbf{r}_{\mathrm{CP}}\right)$ and $\nabla^{2} \rho\left(\mathbf{r}_{\mathrm{CP}}\right)$ for the ring-critical points for both models (see Table S5). A good correlation was also found in these cases and the largest deviations does not exceed 0.02 e $\AA^{-3}$ and 0.3 e $\AA^{-5}$ for $\rho\left(\mathbf{r}_{\mathrm{CP}}\right)$ and $\nabla^{2} \rho\left(\mathbf{r}_{\mathrm{CP}}\right)$, respectively.

\subsection{Electrostatic interaction energies}

In the crystal lattice the quercetin molecule is in direct contact with 19 neighbouring entities (including water molecules). These contacts can be reduced to 13 unique pairs of interacting molecules (eight contacts with other quercetin

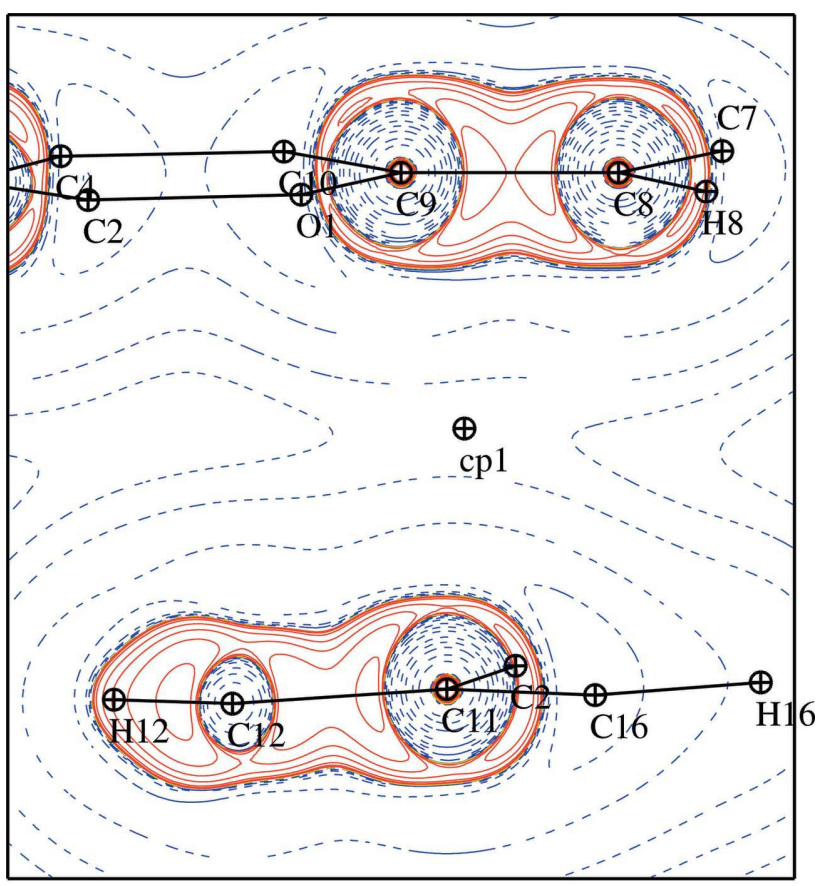

(a)

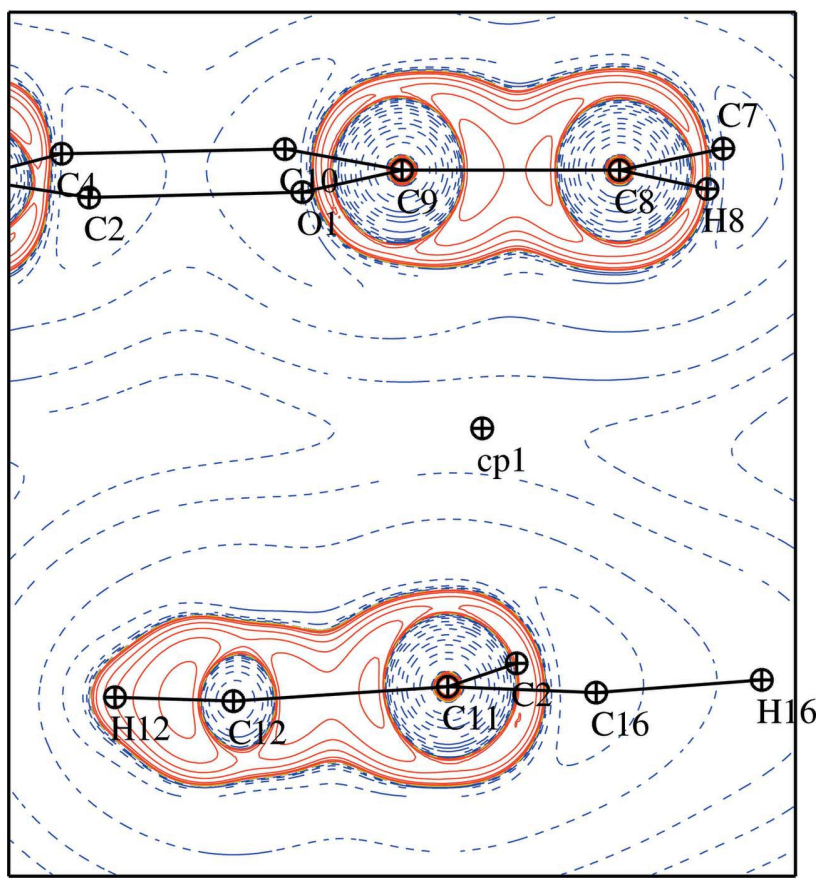

(b)

Figure 10

Laplacian $\left[\nabla^{2} \rho(\mathbf{r})\right]$ maps of representative $\pi \cdots \pi$ interactions from $(a)$ TAAM_OPT and $(b)$ THEO_OPT models. Blue (dashed) and red (solid) lines represent positive and negative values. Contours are drawn at $\pm 2^{m}$ $\times 10^{n}$ e $\AA^{-5}(m=1,2,3 ; n=-3,-2 \ldots)$ levels. Maps are plotted in the plane containing atoms $\mathrm{C} 9, \mathrm{C} 8$ and $\mathrm{C} 11$. 
molecules and five with water molecules). The remaining six interacting pairs are duplicates and correspond to symmetry operations in the crystal lattice which are not involutional (the symmetry operator and its inverse are different). The values of the corresponding electrostatic interaction energies for the TAAM_OPT and THEO_OPT models are given in Table 7. The pairs marked with letters $A-H$ refer to interactions between two quercetin molecules and those with letters $I-M$ refer to interactions between the quercetin and the water molecule. The pairs listed in Table 7 are sorted from the weakest to the strongest, according to their corresponding electrostatic interaction energies. The graphical representation of the interacting pairs of molecules is shown in Fig. 11. The overall agreement between the TAAM_OPT and THEO_OPT models with a coefficient of determination of $R^{2}=0.944$ for all interactions is quite good (see Fig. S8). The greatest difference in electrostatic interaction energy of

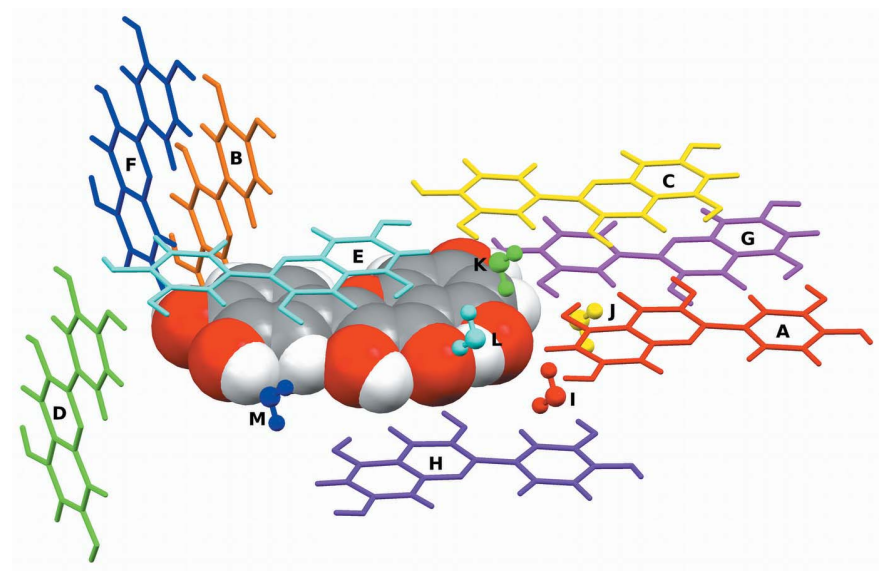

Figure 11

Representation of the unique contacts between the pairs formed by the quercetin molecule and the neighbouring molecules, including the water molecules.
$13 \mathrm{~kJ} \mathrm{~mol}^{-1}$ (14\% in relative value) is noticed for the pair marked with ' $\mathrm{H}$ '. This difference could be attributed to the fact that the $\mathrm{O} 4$ atom was assigned an atom type with low sample size, therefore leading to a possible higher error in the multipolar database. Moreover, this is a very strong hydrogen bond for which a higher discrepancy between theory and experiment can occur (Overgaard et al., 2001).

The total electrostatic energy for the two models agrees well; the values are -291 and $-281 \mathrm{~kJ} \mathrm{~mol}^{-1}$ for TAAM_OPT and THEO_OPT, respectively. The root mean square (r.m.s.) difference of the electrostatic energies between the two models is $\sim 6.4 \mathrm{~kJ} \mathrm{~mol}^{-1}$.

\subsection{Electrostatic potentials}

The three-dimensional electrostatic potential (ESP) envelopes for the quercetin molecule mapped on the $0.0067 \mathrm{e} \AA^{-3}$ $\left(0.001 \mathrm{e} \mathrm{bohr}^{-3}\right)$ isosurface of the electron density are shown in Fig. 12. Once again, a good qualitative agreement is observed between the TAAM_OPT and THEO_OPT models. As expected, the negative surfaces of the ESP are seen in the vicinity of the $\mathrm{O}$ atoms involved in hydrogen bonding and the positive surfaces are located in the proximity of $\mathrm{H}$ atoms. The ESP above the benzopyran moiety is almost zero. The most prominent difference is seen in the region of the catechol ring (C11-C16 and C2 atoms), which displays more negative ESP in the TAAM_OPT model. Small differences are visible for the $\mathrm{O}$ atoms of hydroxyl groups; all $\mathrm{O}$ atoms except $\mathrm{O} 5$ exhibit more negative ESP for the TAAM_OPT model. The atom O1 has more negative ESP for the TAAM_OPT model, whereas the atom $\mathrm{O} 4$ has more positive ESP. These slight variations in ESP distribution around the quercetin molecule seem to correlate well with the interaction energy differences between the models (Table 7). For example, less negative ESP in the vicinity of the $\mathrm{O} 4$ atom for the TAAM_OPT model is mirrored by the contact (marked $H$ ) for which a lower electrostatic interaction energy was obtained.
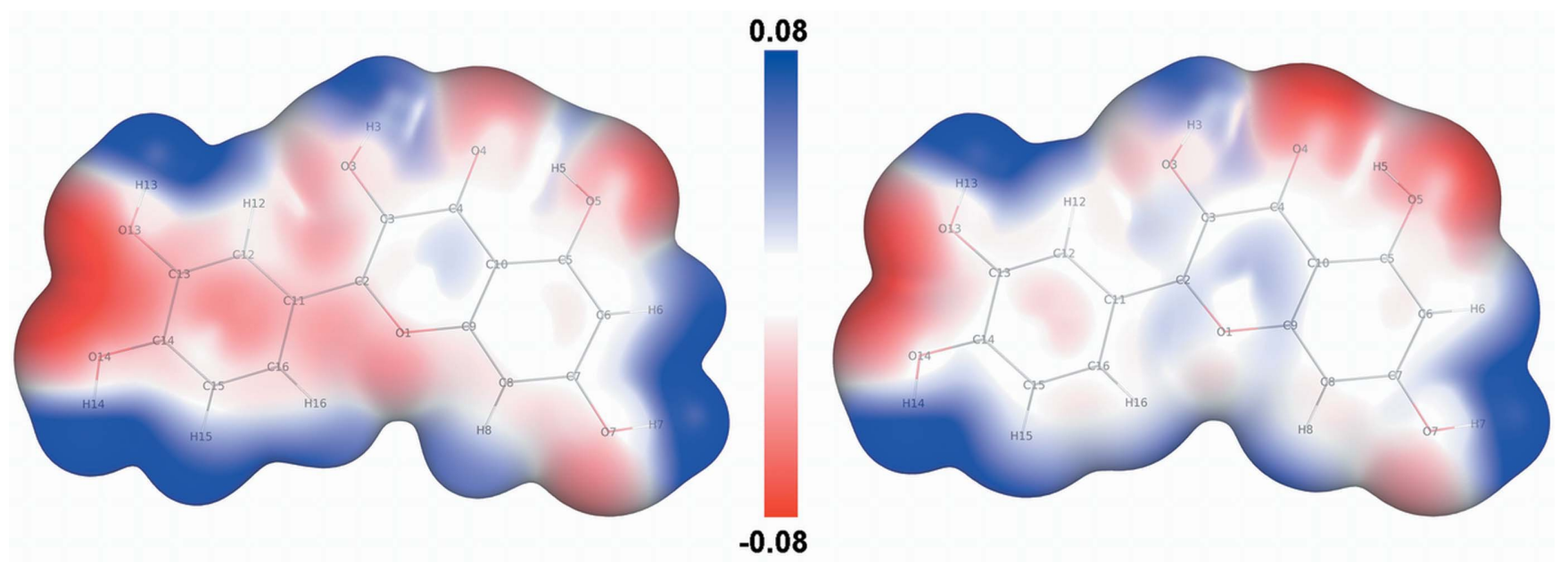

Figure 12

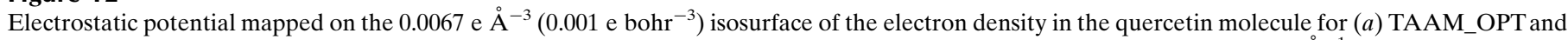
(b) THEO_OPT models. The maximum negative (blue) and positive (red) values of the ESP correspond to 0.08 and -0.08 e $\AA^{-1}$ values. The view was generated using the program Pymol (DeLano, 2002). 
In order to quantify the ESP distribution in the quercetin molecule, the ESP surface quantities were calculated, as proposed by Politzer and co-workers (Murray \& Politzer, 1998; Murray et al., 2000). All the notations used here to describe the quantities are from their original papers. The surface quantities were computed from a three-dimensional grid of points of the electrostatic potential $V_{S}\left(\mathbf{r}_{i}\right)$, with a $0.1 \AA$ step, corresponding to the electron-density surface at the contour level 0.0067 (3) e $\AA^{-3}$. The calculated quantities of the ESP are listed in Table S7. A comparison of different surface quantities resulted in similar values for the TAAM_OPT and THEO_OPT models. The average positive $\bar{V}_{S}^{+}$and negative $\bar{V}_{S}^{-}$potentials are slightly higher in absolute values for the TAAM_OPT model. The average deviation from the overall potential $\Pi$, which can be interpreted as a measure of the local polarity of the molecule, is also only slightly higher in the case of the TAAM_OPT model. The variance of the negative values of the ESP, $\sigma_{-}^{2}=$ $1520\left(\mathrm{~kJ} \mathrm{~mol}^{-1}\right)^{2}$ is the same for the two models. The positive variance of the ESP is higher for the TAAM_OPT model: $\sigma_{+}^{2}=$ $3105\left(\mathrm{~kJ} \mathrm{~mol}^{-1}\right)^{2}$ compared with the THEO_OPT model: $\sigma_{+}^{2}=$ $2744\left(\mathrm{~kJ} \mathrm{~mol}^{-1}\right)^{2}$ and approximately two times larger than $\sigma_{-}^{2}$. The degree of balance $(v)$ between positive and negative surface potentials was found to be comparable for both models but slightly closer to its maximum limit value of 0.25 for the THEO_OPT model. The quantity $v \sigma_{\text {tot }}^{2}$ expresses the overall tendency of the molecule for attractive non-covalent interactions. This surface quantity is very close for both models and is found to be 978 and $1020\left(\mathrm{~kJ} \mathrm{~mol}^{-1}\right)^{2}$ for the TAAM_OPT and THEO_OPT models. All the surface quantities were found to be consistent with the quantities calculated for the non-ionic forms of the molecules (Murray et al., 2000).

\subsection{Atomic charges and dipole moments}

The distribution of atomic charges in quercetin monohydrate, derived from the Hansen-Coppens (Hansen \& Coppens, 1978) multipole formalism, for the TAAM_OPT and THEO_OPT models are listed in Table S6. The largest deviations between the two models are visible for the $\mathrm{O} 4$ atom and the $\mathrm{C}$ atoms of the $\mathrm{C} 5-\mathrm{C} 10$ ring of the benzopyran moiety. However, these small differences (up to 0.24 e for C6) do not change much of the ESP view for this part of the molecule (see Fig. 12).

In order to further assess the accuracy of the TAAM_OPT model the dipole moments for the quercetin and the water molecules for the TAAM_OPT and THEO_OPT models were also calculated. The dipole moments of the quercetin molecule, computed from atomic monopoles and dipoles, are in good agreement for the two models. The values are $3.8 \mathrm{D}$ for the TAAM_OPT model and 4.1 D for THEO_OPT. The direction of the dipole moments for the two models is found to deviate by $\sim 27^{\circ}$ (Fig. S9). Nevertheless, their orientations follow the general distribution of the electrostatic potential as seen in Fig. 12. A similar scenario was observed by Bąk et al. (2009) when the dipole moments were compared from different multipolar models. We also verified the values of dipole moments for the water molecule. For both TAAM_OPT and THEO_OPT models the magnitudes of the dipole moments were equal to $\sim 2.0 \mathrm{D}$ with directions deviating by $\sim 1^{\circ}$. These values were found to be in good accordance with the dipole moments of the water molecule derived from theoretical calculations and multipole modelling of X-ray diffraction data (Spackman et al., 2007).

\section{Concluding remarks}

This work was initiated with the aim of representing the transferred experimental multipolar atom model as an easy and better replacement for the widely used IAM. Indeed the present study on a new crystal structure of quercetin monohydrate determined from X-ray diffraction data convincingly demonstrates that the extended ELMAM database transfer approach greatly improves several factors, such as atomic positions, thermal motions and residual electron densities, when these were compared with the corresponding IAM.

In this process the structure was fully analysed in terms of its geometry, molecular packing and intra- and intermolecular interactions. The Hirshfeld surface analysis of intermolecular contacts confirmed that the $\mathrm{O}-\mathrm{H} \cdots \mathrm{O}$ hydrogen bonds are the dominating contacts in this structure.

A comparison of partially unrestrained models indicates that the $X-\mathrm{H}$ distances are greatly improved in the TAAM_UR model and they are similar to the average neutron values. The quantitative and qualitative representations of thermal motions of non-H atoms via the calculation of similarity indices and PEANUT plots show that they are superior to those obtained from the IAM_R model. The residual electron densities are also significantly reduced in the TAAM_R model.

The charge-density features and derived properties obtained from the transferred and theoretical models are found to be in good agreement. However, the deformation electron-density maps appeared to be a little blurred for the transferred model. This is not surprising as the charge-density parameters of the transferred model were obtained from a database of experimentally derived electron densities and the diffraction data are contaminated by some measurement errors and atomic thermal motion.

Based on the first four KP criteria, all intra- and intermolecular contacts of $\mathrm{O}-\mathrm{H} \cdots \mathrm{O}, \mathrm{C}-\mathrm{H} \cdots \mathrm{O}$ and $\mathrm{H} \cdots \mathrm{H}$ types are classified as hydrogen bonds, except the $\mathrm{C} 12-\mathrm{H} 12 \cdots \mathrm{O} 1 W$ and $\mathrm{H} 16 \cdots \mathrm{H} 15$ contacts. All the $\pi \cdots \pi$ interactions and the $\mathrm{O} \cdots \mathrm{O}$ contacts are found to be of the van der Waals type.

Although the electrostatic potential distributions in the quercetin molecule, especially in the vicinity of the catechol ring, vary a little, the electrostatic interaction energies estimated from the two models agree remarkably well. The magnitude and direction of the dipole moments from the two models are found to vary slightly.

This quantitative and comparative study on the quercetin monohydrate structure demonstrates that in the absence of high-resolution diffraction data the experimental multipolar 
database transfer approach can be applied to estimate the charge density. This electron density is comparable to that obtained from theoretical structure factors using the same multipolar atom model. However, note the limitations of the transferred model, which does not take into account atom polarization owing to local chemical environments. The transfer provides values for the electron-density derived properties (dipole moments, electrostatic potentials and electrostatic interaction energies) only within a transferability approximation. To estimate the accuracy of the predicted properties, analysis of a greater sample of the transferred electron-density parameters for several molecules is required. Work in this direction has been undertaken (Bak et al., 2011).

We would like to thank Bertrand Fournier (CRM2) for improving the electrostatic energy integration algorithm in the VMoPro program. We thank Dr Catherine Humeau for helpful discussions and for the quercetin sample. The support of ANR, Nancy University, Lorraine region (SD) is acknowledged. PM thanks the European Commission for the award of Marie Curie International Incoming Fellowship within the 7th European Community Framework Programme. MA thanks the Higher Education Commission of Pakistan for financial assistance.

\section{References}

Abramov, Yu. A. (1997). Acta Cryst. A53, 264-272.

Allen, F. H., Kennard, O., Watson, D. G., Brammer, L., Orpen, A. G. \& Taylor, R. (1987). J. Chem. Soc. Perkin Trans. 2, pp. S1-S19.

Allen, F. H., Watson, D. G., Brammer, L., Orpen, A. G. \& Taylor, R. (2006). International Tables for Crystallography, Vol. C, ch. 9.5, pp. 790-811. Berlin: Springer.

Bader, R. F. W. (1990). Atoms in Molecules: A Quantum Theory, Oxford University Press.

Bader, R. F. W. (1998). J. Phys. Chem. A, 102, 7314-7323.

Bąk, J. M., Domagała, S., Hübschle, C., Jelsch, C., Dittrich, B. \& Dominiak, P. M. (2011). Acta Cryst. A67. In the press.

Bąk, J. M., Dominiak, P. M., Wilson, C. C. \& Woźniak, K. (2009). Acta Cryst. A65, 490-500.

Becke, A. D. (1988). J. Chem. Phys. 88, 2547-2553.

Becke, A. D. (1993). J. Chem. Phys. 98, 5648-5652.

Brock, C. P., Dunitz, J. D. \& Hirshfeld, F. L. (1991). Acta Cryst. B47, 789-797.

Coppens, P. (1997). X-ray Charge Densities and Chemical Bonding. New York: Oxford University Press.

Cruickshank, D. W. J. (1956). Acta Cryst. 9, 747-753.

DeLano, W. L. (2002). The PyMOL Molecular Graphics System, http://www.pymol.org.

Destro, R., Soave, R., Barzaghi, M. \& Presti, L. L. (2005). Chem. Eur. J. 11, 4621-4634.

Dittrich, B., Hübschle, C. B., Holstein, J. J. \& Fabbiani, F. P. A. (2009). J. Appl. Cryst. 42, 1110-1121.

Dittrich, B., Hübschle, C. B., Luger, P. \& Spackman, M. A. (2006). Acta Cryst. D62, 1325-1335.

Dittrich, B., Hübschle, C. B., Messerschmidt, M., Kalinowski, R., Girnt, D. \& Luger, P. (2005). Acta Cryst. A61, 314-320.

Dittrich, B., Koritsánszky, T. \& Luger, P. (2004). Angew. Chem. Int. Ed. 43, 2718-2721.

Dittrich, B., McKinnon, J. J. \& Warren, J. E. (2008). Acta Cryst. B64, 750-759.

Dittrich, B., Munshi, P. \& Spackman, M. A. (2007). Acta Cryst. B63, 505-509.
Dittrich, B., Strumpel, M., Schäfer, M., Spackman, M. A. \& Koritsánszky, T. (2006). Acta Cryst. A62, 217-223.

Dittrich, B., Weber, M., Kalinowski, R., Grabowsky, S., Hübschle, C. B. \& Luger, P. (2009). Acta Cryst. B65, 749-756.

Domagała, S. \& Jelsch, C. (2008). J. Appl. Cryst. 41, 1140-1149.

Dominiak, P. M., Makal, A., Mallinson, P. R., Trzcińska, K., Eilmes, J., Grech, E., Chruszcz, M., Minor, W. \& Woźniak, K. (2006). Chem. Eur. J. 12, 1941-1949.

Dominiak, P. M., Volkov, A., Dominiak, A. P., Jarzembska, K. N. \& Coppens, P. (2009). Acta Cryst. D65, 485-499.

Dominiak, P. M., Volkov, A., Li, X., Messerschmidt, M. \& Coppens, P. (2007). J. Chem. Theory Comput. 3, 232-247.

Dovesi, R., Saunders, V. R., Roetti, C., Orlandol, R., Zicovich-Wilson, C. M., Pascale, F., Civalleri, B., Doll, K., Harrison, N. M., Bush, I. J., D'Arco, Ph. \& Llunell, M. (2008). CRYSTAL06 1.0, Version 1_0_2. University of Turin, Italy.

ElAttar, T. M. A. \& Virji, A. S. (1999). Anticancer Drugs, 10, 187-194.

Espinosa, E., Alkorta, I., Elguero, J. \& Molins, E. (2002). J. Chem. Phys. 117, 5529-5542.

Faerman, C. H. \& Price, S. L. (1990). J. Am. Chem. Soc. 112, 49154926.

Farrugia, L. J. (1997). J. Appl. Cryst. 30, 565.

Farrugia, L. J., Kočovský, P., Senn, H. M. \& Vyskočil, Š. (2009). Acta Cryst. B65, 757-769.

Formica, J. V. \& Regelson, W. (1995). Food Chem. Toxicol. 33, 10611080.

Fournier, B., Bendeif, E.-E., Guillot, B., Podjarny, A., Lecomte, C. \& Jelsch, C. (2009). J. Am. Chem. Soc. 131, 10929-10941.

Gatto, M. T., Falcocchio, S., Grippa, E., Mazzanti, G., Battinelli, L., Nicolosi, G., Lambusta, D. \& Saso, L. (2002). Bioorg. Med. Chem. 10, 269-272.

Gryglewski, R. J., Korbut, R., Robak, J. \& Swies, J. (1987). Biochem. Pharmacol. 36, 317-322.

Guillot, B., Viry, L., Guillot, R., Lecomte, C. \& Jelsch, C. (2001). J. Appl. Cryst. 34, 214-223.

Hansen, N. K. \& Coppens, P. (1978). Acta Cryst. A34, 909-921.

Hariharan, P. C. \& Pople, J. A. (1973). Theor. Chim. Acta, 28, 213-222.

Hirshfeld, F. L. (1971). Acta Cryst. B27, 769-781.

Hirshfeld, F. L. (1976). Acta Cryst. A32, 239-244.

Hohenberg, P. \& Kohn, W. (1964). Phys. Rev. B, 136, 864-871.

Hummel, W., Hauser, J. \& Bürgi, H. B. (1990). J. Mol. Graphics, 8, 214-218.

Jelsch, C., Guillot, B., Lagoutte, A. \& Lecomte, C. (2005). J. Appl. Cryst. 38, 38-54.

Jelsch, C., Pichon-Pesme, V., Lecomte, C. \& Aubry, A. (1998). Acta Cryst. D54, 1306-1318.

Jin, G.-Z., Yamagata, Y. \& Tomita, K. (1990). Acta Cryst. C46, 310 313.

Johnson, C. K. \& Burnett, M. N. (1996). ORTEPIII. Report ORNL6895. Oak Ridge National Laboratory, Tennessee, USA.

Koch, U. \& Popelier, P. L. A. (1995). J. Phys. Chem. 99, 9747-9754.

Koritsánszky, T. \& Coppens, P. (2001). Chem. Rev. 101, 1583-1628.

Lamson, D. W. \& Brignall, M. S. (2000). Altern. Med. Rev. 5, 196-208.

Le Page, Y. \& Gabe, E. J. (1979). J. Appl. Cryst. 12, 464-466.

Lebedev, V. I. \& Laikov, D. N. (1999). Dokl. Math. 59, 477-481.

Lee, C., Yang, W. \& Parr, R. G. (1988). Phys. Rev. B, 37, 785-789.

Leopoldini, M., Marino, T., Russo, N. \& Toscano, M. (2004). Theor. Chem. Acc. 111, 210-216.

Mallinson, P. R., Smith, G. T., Wilson, C. C., Grech, E. \& Woźniak, K. (2003). J. Am. Chem. Soc. 125, 4259-4270.

Mata, I., Alkorta, I., Molins, E. \& Espinosa, E. (2010). Chem. Eur. J. 16, 2442-2452.

McKinnon, J. J., Jayatilaka, D. \& Spackman, M. A. (2007). Chem. Commun. pp. 3814-3816.

McKinnon, J. J., Spackman, M. A. \& Mitchell, A. S. (2004). Acta Cryst. B60, 627-668.

Munshi, P. \& Guru Row, T. N. (2005a). Crystallogr. Rev. 11, 199-241. Munshi, P. \& Guru Row, T. N. (2005b). CrystEngComm, 7, 608-611. 
Munshi, P., Jelsch, C., Hathwar, V. R. \& Guru Row, T. N. (2010). Cryst. Growth Des. 10, 1516-1526.

Munshi, P., Madsen, A. Ø., Spackman, M. A., Larsen, S. \& Destro, R. (2008). Acta Cryst. A64, 465-475.

Munshi, P., Skelton, W., McKinnon, J. J. \& Spackman, M. A. (2008). CrystEngComm, 10, 197-206.

Murray, J. S., Peralta-Inga, Z. \& Politzer, P. (2000). Int. J. Quantum Chem. 80, 1216-1223.

Murray, J. S. \& Politzer, P. (1998). J. Mol. Struct. Theochem, 425, 107114.

Nöthlings, U., Murphy, S. P., Wilkens, L. R., Henderson, B. E. \& Kolonel, L. N. (2007). Am. J. Epidemiol. 166, 924-931.

Olejniczak, S. \& Potrzebowski, M. (2004). J. Org. Biomol. Chem. 2, 2315-2322.

Overgaard, J., Schiøtt, B., Larsen, F. K. \& Iversen, B. B. (2001). Chem. Eur. J. 7, 3756-3767.

Oxford Diffraction (2009). CrysAlisPro. Oxford Diffraction Ltd, Yarnton, England.

Pichon-Pesme, V., Jelsch, C., Guillot, B. \& Lecomte, C. (2004). Acta Cryst. A60, 204-208.

Pichon-Pesme, V., Lecomte, C. \& Lachekar, H. (1995). J. Phys. Chem. 99, 6242-6250.

Popelier, P. (2000). Atoms in Molecules. An Introduction. Harlow: Prentice Hall.

Rossi, M., Rickles, L. F. \& Halpin, W. A. (1986). Bioorg. Chem. 14, 55-69.
Roversi, P. \& Destro, R. (2004). Chem. Phys. Lett. 386, 472-478.

Sheldrick, G. M. (2008). Acta Cryst. A64, 112-122.

Shoskes, D. A., Zeitlin, S. I., Shahed, A. \& Rajfer, J. (1999). Urology, 54, 960-963.

Spackman, M. A. (1992). Chem. Rev. 92, 1769-1797.

Spackman, M. A. (1997). Annu. Rep. Prog. Chem. Sect. C Phys. Chem. 94, 177-207.

Spackman, M. A. \& Jayatilaka, D. (2009). CrystEngComm, 11, 19-32.

Spackman, M. A. \& McKinnon, J. J. (2002). CrystEngComm, 4, 378392.

Spackman, M. A., Munshi, P. \& Dittrich, B. (2007). ChemPhysChem, 8, 2051-2063.

Treutler, O. \& Ahlrichs, R. (1995). J. Chem. Phys. 102, 346-354.

Tsirelson, V. G. \& Ozerov, R. P. (1996). Electron Density and Bonding in Crystals. Bristol: Institute of Physics Publishing.

Volkov, A., Li, X., Koritsánszky, T. S. \& Coppens, P. (2004). J. Phys. Chem. A, 108, 4283-4300.

Volkov, A., Messerschmidt, M. \& Coppens, P. (2007). Acta Cryst. D63, 160-170.

Whitten, A. E. \& Spackman, M. A. (2006). Acta Cryst. B62, 875-888.

Williams, T. et al. (2009). gnuplot4.2, http://www.gnuplot.info/.

Wolff, S. K., Grimwood, D. J., McKinnon, J. J., Jayatilaka, D. \& Spackman, M. A. (2007). CrystalExplorer2.0. University of Western Australia, Perth, http://hirshfeldsurface.net/.

Zarychta, B., Pichon-Pesme, V., Guillot, B., Lecomte, C. \& Jelsch, C. (2007). Acta Cryst. A63, 108-125. 